\title{
El metabolismo social en las economías andinas y centroamericanas, 1970-2013 ${ }^{1}$
}

\section{Social Metabolism in the Andean and Central American Economies, 1970-2013}

\author{
Zulma Crespo-Marín \\ Universidad del Valle - Instituto Cinara \\ zulma.crespo@correounivalle.edu.co \\ https://orcid.org/0000-0002-8820-9284 \\ Mario Pérez-Rincón ${ }^{3}$ \\ Universidad del Valle - Instituto Cinara \\ mario.perez@correounivalle.edu.co \\ https://orcid.org/0000-0003-2628-2360
}

Recibido: 14-11-2017 Aprobado: 26-10-2018

1 Este artículo es producto del proyecto "Metabolismo social y conflictos ambientales en países andinos y centroamericanos" (Mesoca-Anca), financiado por la Universidad del Valle (Proyecto No. CI 2826).

2 Economista.

3 Doctor en Ciencias Ambientales. 


\section{Resumen}

Este artículo compara los perfiles económico-metabólicos de la región Andina y la Centroamericana. Usando el análisis de flujo de materiales (MFA), se construyen indicadores biofísicos (1970-2013) y se complementan con indicadores monetarios. Se analiza la especialización productiva, los patrones extractivos y de comercio, y se mide la existencia de desacoplamiento. Monetariamente hay un proceso de reprimarización y desindustrialización en los Andes y un incremento de los servicios en Centroamérica. Metabólicamente hay materialización absoluta de ambas regiones por un cambio de patrón metabólico hacia: i) combustibles fósiles y minerales en el caso andino; ii) biomasa agrícola y materiales de construcción en Centroamérica. Ello evidencia una transición hacia un régimen urbano-industrial, más acentuado en la zona andina que en Centroamérica y con mayor énfasis hacia el mercado externo en la primera. La hipótesis de desacoplamiento no se cumple en varios años en ambas regiones analizadas. Estas dinámicas incrementan las presiones ambientales sobre los territorios.

Palabras clave: flujo de materiales; desacoplamiento; metabolismo social; región Andina; región Centroamericana.

Clasificación JEL: N56, Q32, Q56, Q57.

\section{Abstract}

This article compares the economic and metabolic profiles of the Andean region and Central America by applying Biophysical indicators based on the methodology of Material Flow Analysis (MFA) to data between 1970 and 2013 , complemented with monetary indicators. First, productive specialization, extractive patterns of both regions and their material trade patterns are analysed; later on, the existence of points of decoupling are measured. Monetarily speaking, there is a reprimarization and deindustrialization in Andes and a rise in the providing of services in Latin America. In metabolic terms, there is an absolute objectification of both regions due to a change in metabolic patterns towards: i) Fossil fuels and minerals in the case of the Andes. ii) Agricultural biomass and construction materials in Central America. This is evidence of a transition towards an urban-industrial regime, more present in the Andean zone and with a bigger stress on external market. The hypothesis of decoupling is only fulfilled within years in both analysed regions. These dynamics increase environmental pressures on these territories.

Keywords: Material Flow Analysis, Decoupling, Social metabolism, Andean region, Central American region. 


\section{Introducción}

La economía no solo se expresa en términos monetarios, también tiene una contraparte biofísica y metabólica.Los procesos de producción, consumo e intercambio se sostienen a través de un flujo de energía, materiales y servicios ecológicos que son provistos por el medio ambiente (Falconí, Vallejo y Burbano, 2006). La economía ecológica incorpora al análisis económico la perspectiva biofísica mediante el concepto de metabolismo social $^{4}$, término adoptado de la biología, extendiendo la idea del perfil metabólico propio de los organismos vivos, al funcionamiento de las economías y de la sociedad (Ayres y Kneese, 1969; Ayres y Simonis, 1994; Fisher-Kowalski, 1997; Fisher-Kowalski \& Haberl, 2015; Infante, González y Toledo, 2017).

La economía ecológica entiende la economía como un subsistema abierto a la entrada de energía y materiales y a la salida de residuos y energía disipada; esta hace parte de un sistema más grande y finito que corresponde a la biosfera (Martínez-Alier, 2011). El rápido crecimiento del subsistema económico mundial, jalonado por el aumento del consumo y la población, genera un incremento del metabolismo social que afecta progresivamente el sistema natural. De tal manera, el crecimiento del consumo socio-económico de materia y energía y la generación de desperdicios son el corazón de los problemas ambientales y también los determinantes de los conflictos socio-ambientales.

En esa perspectiva, el concepto de metabolismo social se utiliza con dos objetivos: primero, expresar la dependencia del sistema socio-económico del medio natural para su funcionamiento $\mathrm{y}$, segundo, demostrar que la velocidad de producción, extracción y consumo de recursos de la economía ha superado la capacidad de soporte y reproducción natural, expandiendo los impactos y conflictos ambientales hacia vastos

4 Analogía o metáfora biológica primeramente utilizada por Marx para ilustrar la circulación de las mercancías, y de manera más general como un "intercambio entre hombre y tierra" (Martínez-Alier, 2004, citado por González de Molina y Toledo, 2014, p. 47). territorios. De ahí surge la idea de sustentabilidad, la cual se planteó en principio como la necesidad de un desarrollo que asegurara la satisfacción de las necesidades del presente sin comprometer las de las futuras generaciones (Brundtland, 1989). Sin embargo, esta definición fue rebatida y calificada como ambigua (Gudynas, 2011), surgiendo varias corrientes con miradas distintas, dentro de las que se destacan la "sustentabilidad débil" y su contraparte la "sustentabilidad fuerte" (Daly, 1996; Daly y Farsey, 2004).

La primera reconoce la necesidad de promover un desarrollo que no destruya la base ecológica, y defiende la idea de que los impactos negativos ambientales pueden ser compensados por el crecimiento económico o resueltos por el desarrollo tecnológico. Se cataloga como débil, porque no da un tratamiento especial al capital natural, y evade el problema de su agotamiento, al suponer que otras formas de capital y el progreso tecnológico siempre podrán compensarlo o sustituirlo (Cabeza, 1996; Martínez-Alier y Roca, 2013; Victor, 1991). La sustentabilidad fuerte parte del hecho de considerar la imposibilidad de sustitución de muchas de las funciones y servicios ambientales, por lo cual considera que el capital creado por la sociedad y el capital natural más que sustituibles son complementarios. Mientras que en la sustentabilidad débil la solución al conflicto entre ambiente y desarrollo es endógena, es decir, el modelo corrige sus desequilibrios a través de precios y tecnología, en la sustentabilidad fuerte, la solución es exógena al modelo, es decir, requiere un cambio de paradigma que corrija al modelo (Pérez, Rojas y Ordóñez, 2016).

Desde el punto de vista de la economía convencional (sustentabilidad débil), la sustentabilidad se mide con indicadores monetarios (por ejemplo, el "PIB verde ecológicamente ajustado"), en contraste con la sustentabilidad fuerte que utiliza indicadores biofísicos (Martínez-Alier, 1995). Los indicadores biofísicos miden la presión que ejerce la actividad socio-económica sobre el espacio ambiental; articulados con los indicadores monetarios permiten contrastar la estructura biofísica de los países con las políticas de crecimiento y demás dinámicas socioeconómicas (Pérez-Rincón, 
2008, p. 52). Los métodos de estudio del metabolismo social se centran en la contabilidad de los flujos de energía, materiales y residuos que van a través de la economía, incluyendo los flujos de agua reales y "virtuales", la huella hídrica, la huella ecológica, la HANPP (human appropriation of net primary production), entre otros, convirtiéndose en instrumentos para la gestión de la sustentabilidad. El análisis de flujo de materiales (MFA) 5 es uno de los principales métodos para estudiar el metabolismo social y llegar a los indicadores biofísicos mencionados (Hák, Moldan y Dahl, 2012; Martínez-Alier, 2011).

El MFA es una propuesta metodológica que forma parte de los sistemas satelitales de cuentas de recursos naturales; y es utilizada por la ecología industrial y la economía ecológica para cuantificar los procesos de extracción, intercambio y consumo de recursos naturales (Vallejo, 2015). En Europa, investigaciones como la de Weisz et al. (2006) presentan cuantificaciones completas de la base material de las economías europeas; Behrens, Giljum, Kovanda y Niza (2007), por su parte, presentó el primer estudio global, haciendo alusión a la creciente importancia de Asia y América Latina como regiones proveedoras de recursos naturales para la economía mundial. De igual forma, otros trabajos sobre metabolismo social y contabilidad biofísica se han concentrado en el desplazamiento de la carga ambiental, incluyendo los flujos físicos de comercio directos e indirectos (Dittrich y Bringezu, 2010; Dittrich, Bringezu y Schutz, 2012). En los países miembros de la Unión Europea esta metodología ha sido utilizada no solo académicamente, sino que ha sido incluida en las estadísticas oficiales gubernamentales ${ }^{6}$.

6 Hay que resaltar que los primeros trabajos realizados sobre metabolismo material fueron los de Ayres y Kneese (1969), a finales de la década de 1960, quienes proponían ver la contaminación ambiental y su control como un "problema de balance de materiales" de la economía; posteriormente Georgescu-Roegen (1971) discute el problema del incremento de desperdicios y emisiones como un proceso ligado a la producción entrópica. Incluso, desde la antigua Unión Soviética, Gofman et al. (1974, citado por Fischer-Kowalski y Haberl, 2015, p. 112) articulan una crítica análoga de la planificación económica estatal proponiendo un MFA para Rusia.
En América Latina, los estudios de la región se han concentrado en demostrar el deterioro social y ambiental que han generado las políticas económicas liberalizadoras y extractivistas. Una parte de las investigaciones se han focalizado en el estudio individual de países, detallando los flujos de extracción y comercio y discutiendo los modelos productivos. En Chile (Giljum, 2004); Ecuador (Vallejo, 2010); Colombia (Pérez-Rincón, 2006; Vallejo, Pérez-Rincón y Martínez-Alier, 2011) y Argentina (Manrique, Brun, González-Martínez, Walter y Martínez-Alier, 2013). Otros trabajos han hecho comparativos entre los países de la región como es el caso de Muñoz, Giljum y Roca (2009) y Russi et al. (2008). Sin embargo, muy pocos se han dirigido a hacer comparaciones entre diferentes subregiones de AL. Este artículo pretende llenar este vacío comparando los perfiles metabólicos de dos grandes subregiones: la región Andina y la Centroamericana ${ }^{7}$.

El trabajo está organizado de la siguiente manera: después de esta introducción, se presenta la metodología utilizada para la construcción de las estadísticas de flujos de materiales; posteriormente, la caracterización socio-económica de las regiones estudiadas donde se describen las tendencias crematísticas $^{8}$; sigue la presentación de resultados que incluye el análisis de los patrones extractivos materiales, se exploran las tendencias de los flujos de comercio y se miden los niveles de intensidad material para conocer la existencia o no de desacoplamiento de estas economías. Se finaliza con las conclusiones.

\section{Metodología y fuentes}

El análisis de flujo de materiales (MFA) representa las interacciones entre la economía y el ambiente, a través de un balance de materiales que refleja la primera ley de la termodinámica, en la cual se afirma que la materia y la energía no se crean ni

7 Estas dos regiones hacen parte del proyecto Mesoca-Anca que financió esta investigación.

8 Aristóteles define en su obra Política la crematística como el estudio de la formación de los precios para referirse a la dimensión monetaria del proceso económico (Rossi, 2007). 
se destruyen, sino que se transforman. De esta manera se busca que las entradas totales, es decir, los insumos productivos coincidan con la suma de las salidas en forma de emisiones y residuos, más la acumulación de bienes presentes en la economía (Giljum, 2003) (Figura 1).

El análisis de flujo de materiales (MFA) mide los inputs o entradas de materia en unidades físicas de peso -tonelada métrica-, clasificando los materiales extraídos del territorio nacional en biomasa, minerales, materiales de construcción y combustibles fósiles. Los productos importados y exportados tienen la misma clasificación. A partir de contabilizar todos estos materiales, se calculan los indicadores biofísicos que permiten medir la presión ambiental generada por la actividad económica, complementando el sistema de cuentas nacionales.

El presente trabajo sigue las directrices establecidas en la metodología elaborada por la Oficina de Estadísticas de la Unión Europea, Economy Wide Material Flow Accounts (Eurostat, 2013) (Tabla 1). Los indicadores extensivos utilizados en este análisis corresponden a extracción doméstica (DE), es decir, todos los materiales extraídos (excepto el agua y el aire) del territorio nacional para ser incorporados en el proceso económico. Insumo directo de materiales (DMI) equivale a las toneladas de DE más las toneladas importadas, es decir, incluye todo el material que entra a circular como insumo en la economía de un país. Este indicador mide la presión ambiental que ejerce la actividad económica en términos de entrada de materiales en un territorio.

El consumo doméstico de material (DMC) equivale a la cantidad anual de DMI, menos las exportaciones $(\boldsymbol{X})$ en términos físicos. Este indicador permite identificar la presión que ejercen las actividades de consumo sobre el espacio ambiental de un territorio específico. El balance comercial biofísico (PTB) por su parte, es el principal indicador en el análisis del comercio exterior; se calcula descontando de las importaciones $(\boldsymbol{M})$, las exportaciones $(\boldsymbol{X})$. Este indicador permite identificar las transferencias de costos o cargas ambientales entre países o regiones asociados al funcionamiento del sistema económico global y de su comercio internacional (Krausmann et al., 2015).

Por su parte, los indicadores intensivos ayudan a compensar las diferencias de tamaño de las economías, sus territorios y sus poblaciones. $\mathrm{Al}$ respecto se trabaja con la intensidad per cápita, la intensidad de área $\left(\mathrm{km}^{2}\right)$ y la intensidad material por unidad de PIB (Krausmann et al., 2015). Esta última es un indicador de eficiencia material definido como la relación entre DMI y PIB, mostrando la cantidad de toneladas requeridas para producir una unidad de producto, es decir el nivel material del PIB. Su evolución permite saber el grado de desacoplamiento o acoplamiento ambiental de una economía (Riechmann, 2006).

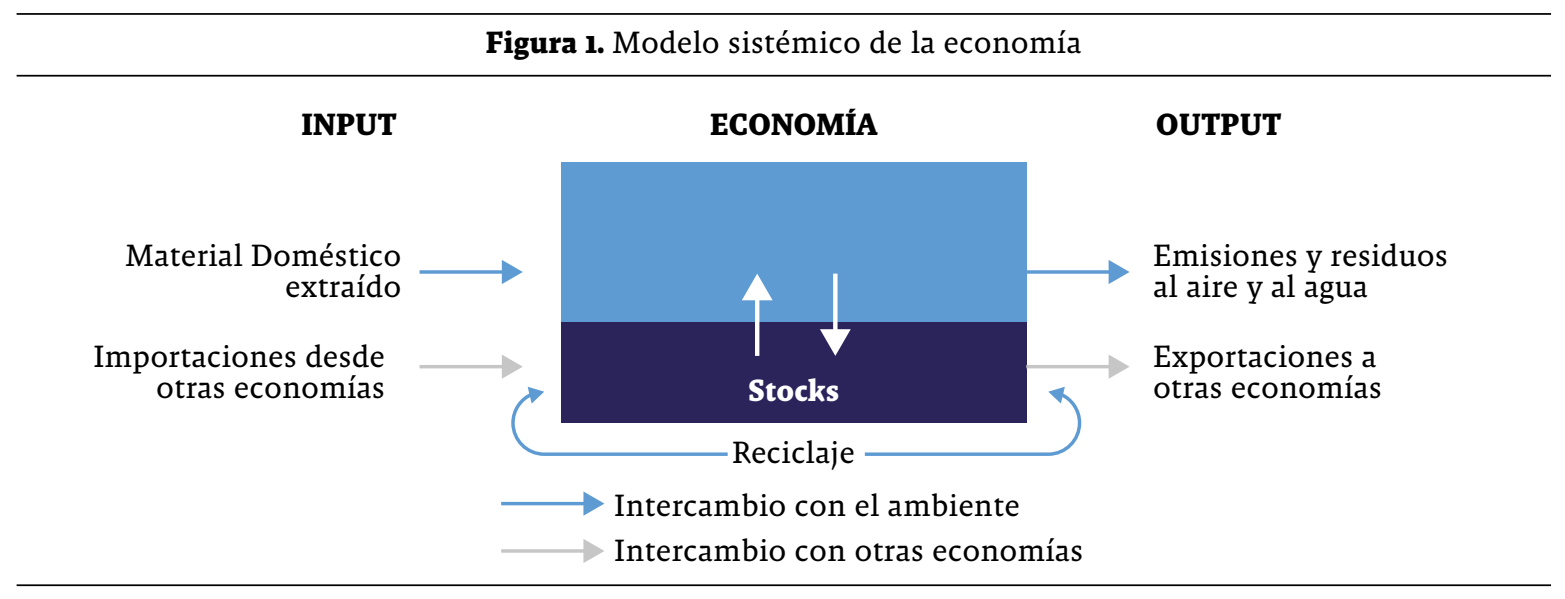

Fuente: Adaptada de Eurostat (2007). 
Tabla 1. Descripciones y fuentes de información

\begin{tabular}{|c|c|c|}
\hline \multicolumn{3}{|c|}{ Clasificación del flujo de materiales } \\
\hline Categoría o material & Descripción & Fuente \\
\hline Biomasa & $\begin{array}{l}\text { Material orgánico extraído y consumido por las personas y el ganado } \\
\text { en un año. }\end{array}$ & \\
\hline Cultivos primarios & $\begin{array}{l}\text { Cereales, raíces y tubérculos, legumbres, cultivos oleaginosos, hortal- } \\
\text { izas, frutas, nueces, fibras y otros cultivos. }\end{array}$ & FAO (2015a) \\
\hline Cultivos forrajeros & Residuos de cultivos de cereales y/o caña de azúcar. & FAO (2015a) \\
\hline $\begin{array}{l}\text { Biomasa de pastoreo } \\
\text { de ganado }\end{array}$ & $\begin{array}{l}\text { Demanda total por pastos de todos los tipos de ganado, expresada en } \\
\text { unidades ganaderas (UG). }\end{array}$ & FAO (2015a) \\
\hline Biomasa forestal & $\begin{array}{l}\text { Madera talada de bosques, plantaciones o tierras agrícolas: carbón } \\
\text { vegetal, madera en rollo, madera en rollo industrial. }\end{array}$ & FAO (2015a) \\
\hline Biomasa pesquera & Captura de peces, crustáceos, moluscos e invertebrados acuáticos. & FAO (2015b) \\
\hline Minerales & & \\
\hline Minerales metálicos & $\begin{array}{l}\text { Minerales ferrosos y no ferrosos medidos en su contenido metálico } \\
\text { bruto. }\end{array}$ & USGS (2015) \\
\hline $\begin{array}{l}\text { Minerales } \\
\text { industriales }\end{array}$ & Minerales medidos en su contenido. & USGS (2015) \\
\hline $\begin{array}{l}\text { Material de } \\
\text { construcción }\end{array}$ & $\begin{array}{l}\text { Arena y grava para producción de concreto y asfalto, junto a otros } \\
\text { materiales como piedras. }\end{array}$ & $\begin{array}{l}\text { USGS (2015); UNSD } \\
\text { (2015) }\end{array}$ \\
\hline Combustibles fósiles & Producción de energía fósil: carbón, petróleo y gas natural. & $\begin{array}{l}\text { EIA (2015); USGS } \\
(2015)\end{array}$ \\
\hline $\begin{array}{l}\text { Comercio } \\
\text { internacional } \\
\text { biofísico }\end{array}$ & $\begin{array}{l}\text { Importación y exportación, datos clasificados por nivel de procesa- } \\
\text { miento (CIIU Rev. l) y el principal componente material. }\end{array}$ & UNSD (2015) \\
\hline
\end{tabular}

\section{Caracterización socio- económica de las regiones Andina y Centroamericana ${ }^{9}$}

\subsection{Región Andina}

La región Andina está constituida por cinco países: Venezuela, Colombia, Ecuador, Perú y Bolivia; juntos integran un área aproximada de 469,4 millones de hectáreas ${ }^{10}$ o 4,7 millones de $\mathrm{km}^{2}$ (Cepal,

9 En algunos casos, los datos monetarios corresponden al período 1990-2012, pues no existía información completa para todos los países a 2013.

10 Para estimar el área de las regiones se realizó la sumatoria simple de los datos de la superficie total que es la superficie terrestre más la superficie de las aguas continentales de 2015a). La población total de la región en 2012 era de 132,8 millones de habitantes" ${ }^{11}$, de los cuales $23 \%$ correspondía a población rural (Celade, 2014). Esto arroja una densidad poblacional de 0,28 personas por hectárea. En la Figura 2 se observa la dinámica de la población desde 1970 hasta 2012, con una tasa de crecimiento anual de 2,1\%.

El PIB de la región, por su parte, pasó de 356,2 billones de dólares en 1970 a 1.030,2 billones

\footnotetext{
los países andinos y países centroamericanos.
}

11 El total de la población regional andina y centroamericana fue calculado a partir de las proyecciones poblacionales por país para 2012 publicadas por Celade (2014). 
en 2012 (precios constantes de 2005, PPA ${ }^{12}$ ), creciendo a una tasa compuesta anual de $2,6 \%$. Al relacionar esta dinámica económica con el crecimiento de la población, arroja una tasa de incremento del PIB per cápita para el período de $0,5 \%$ anual, lo que equivale a un acumulado de solo $23 \%$ en los 42 años analizados. Sin embargo, durante la década de 1980 y hasta finales de la de 1990 , la tasa de crecimiento poblacional fue mayor que la de crecimiento del PIB; ello generó una tendencia negativa del PIB per cápita en este lapso de tiempo (Figura 2). La primera parte, que corresponde a la "década perdida" de América Latina -la de 1980-, sumió a casi toda la región en una gran crisis económica ocasionada por la abultada deuda externa (Ocampo, 2011). En la década de 1990, la tendencia negativa se explica principalmente por el comportamiento de Venezuela, Colombia y Perú que sufrieron crisis económicas a finales de esta década (Ocampo, 2001; Cuba, 2005).

Referente a la estructura del PIB, se observa un aumento del peso del sector primario a partir de finales de los años de 1990 (Figura 3). Mientras en 1990 el sector primario-extractivo compuesto por la actividad agropecuaria y minera, ocupaba en la región el 21\% del PIB total, para 1998 este cae a $14 \%$. A partir de allí, como consecuencia de las reformas neoliberales que flexibilizaron el sector extractivo, se incrementó la participación del sector hasta $24 \%$ en 2014 . Además, se acentúo en el sector primario una reespecialización hacia la actividad minera y petrolera, desplazando la importancia del sector agropecuario en el PIB primario de $46 \%$ a $26 \%$ entre 1990 y 2014 . En este mismo contexto, se produce una pérdida de peso del sector industrial dentro del PIB de la región al caer de $21 \%$ a $13 \%$ en el mismo período. Algunos autores señalan que esto significa una desindustrialización de las economías (Clavijo, Vera y Fandiño, 2012; Gudynas, 2011; Nadal, 2011; Ortiz y Uribe, 2012). Otros autores, por el contrario, afirman que la pérdida de peso del sector industrial dentro del PIB puede deberse a la "desintegración vertical" que ocurre en

12 Los billones corresponden a la expresión anglosajona (mil millones). el sector, explicada en buena medida por el modelo de outsourcing que traslada la actividad de ciertos servicios al sector terciario. Estos son los casos como la vigilancia, el aseo y la contabilidad, entre otros. Esto hace que el valor agregado generado por estas actividades ya no sea parte del PIB industrial sino del PIB de servicios (Carranza y Moreno, 2013; Carranza, González y Serna, 2014; Marsh, 2012). El mismo Ortiz (2016) reposta esta argumentación, mostrando que para el caso de Colombia, por ejemplo, las tendencias de desindustrialización son continuas desde 1974, acentuadas con la apertura comercial de los años de 1990, y se evidencian también en los indicadores absolutos como el empleo y la creación de nuevos establecimientos industriales que tienen la misma tendencia decreciente ${ }^{13}$. Por su parte, el sector de la construcción duplicó su participación de $4 \%$ a $8 \%$ en este lapso de tiempo. Las actividades relacionadas con la administración pública, defensa y servicios sociales y de salud, aumentaron levemente su importancia, mientras la intermediación financiera y actividades inmobiliarias perdieron peso en el PIB.

A lo largo del período, lo que evidencian las cifras es que como resultado de las políticas flexibilizadoras del mercado en los años de 1990, en toda América Latina y el Caribe (ALC) y en los países Andinos, se desarrolló un proceso de especialización productiva que redujo la importancia del sector industrial como generador de producto, empleo

13 "Aunque hay críticas a esta caracterización asociadas a los problemas de medición y contabilidad, dentro de los cuales está la desintegración vertical del sector industrial por la tercerización de algunos servicios del sector; sin embargo, cuando se utiliza un indicador de cantidades, como la participación de la industria manufacturera formal en el empleo total, se obtiene la misma relación pendular de la actividad manufacturera. Ambos indicadores (PIB manufacturero $^{\prime}$ $\mathrm{PIB}_{\text {total }}$ y empleo manufacturero (empleo total $_{\text {ind }}$ indican que de 1925 a 1974 hubo industrialización, y en adelante hubo desindustrialización. Por si faltaren argumentos para sustentar la pendularidad del proceso de transformación industrial, cabe mencionar que la creación de establecimientos industriales se expande sistemáticamente de los años de 1930 (cinco plantas nuevas por año) a los de 1980 (600 plantas nuevas por año), para luego caer abruptamente hasta 57 plantas nuevas en 2001" (Ortiz, 2016, p. 109). 
y negocios y fortaleció la relevancia del sector primario en la región. Este punto de inflexión en la dinámica productiva de estos países y en sus políticas se refleja en un cambio estructural de su aparato productivo y de la canasta exportadora, consolidando el protagonismo de la extracción de minerales y la explotación de hidrocarburos en la escena económica de la zona andina (Pérez-Rincón, Crespo-Marín y Vargas-Morales, 2017).

\subsection{Región Centroamericana}

La región Centroamericana está compuesta por seis países: Guatemala, El Salvador, Honduras, Nicaragua, Costa Rica y Panamál14 y cuenta con un área de 49,9 millones de hectáreas o 0,5 millones de $\mathrm{km}^{2}$ (Cepal, 2015a). Esta región tenía en 2012, 48,8 millones de habitantes, de los cuales $38 \%$ vivía en zona rural. Mientras su densidad poblacional era de 0,87 personas por hectárea, la tasa anual de crecimiento de la población fue de 2,2\% (Figura 4).

El PIB aumentó de US\$46 billones en 1970 a US\$192 billones en 2012, mostrando una tendencia

14 Este análisis excluye a Belice. creciente a un ritmo de 3,5\% promedio anual durante todo el período; sin embargo, las economías centroamericanas experimentaron entre $1980 \mathrm{y}$ 1988 una disminución en su crecimiento debido a la crisis de la deuda que afectó a casi todos los países de América Latina. Al revisar la dinámica del PIB per cápita se encuentra que esta dobló el crecimiento del PIB andino, alcanzando una tasa de 1,2\% anual (Figura 4). La estructura del PIB en Centroamérica ha sido más estable. En términos de pérdida de importancia, los cambios más significativos se presentan en la actividad primaria que cae de $14 \%$ a $9 \%$ y la actividad industrial de $18 \%$ a $14 \%$. Por su parte, las actividades que más han ganado peso son las relacionadas con el sector financiero, la administración pública, la defensa y el comercio. Estas tres actividades pasaron de $50 \%$ a $55 \%$ entre 1990 y 2014 (Figura 5).

\subsection{Comparación entre regiones}

$\mathrm{Al}$ contrastar los datos de ambas regiones, se encuentra lo siguiente: en superficie, la región Andina es 9,4 veces más grande que la región Centroamericana; sin embargo, en tamaño de la economía es solo 5,4 veces mayor. En cuanto al

Figura 2. Tendencias económicas y demográficas

Región Andina (1970-2012). PIB medido en dólares a precios constantes (2005) con PPA. PIB y población países andinos (1970-2012)

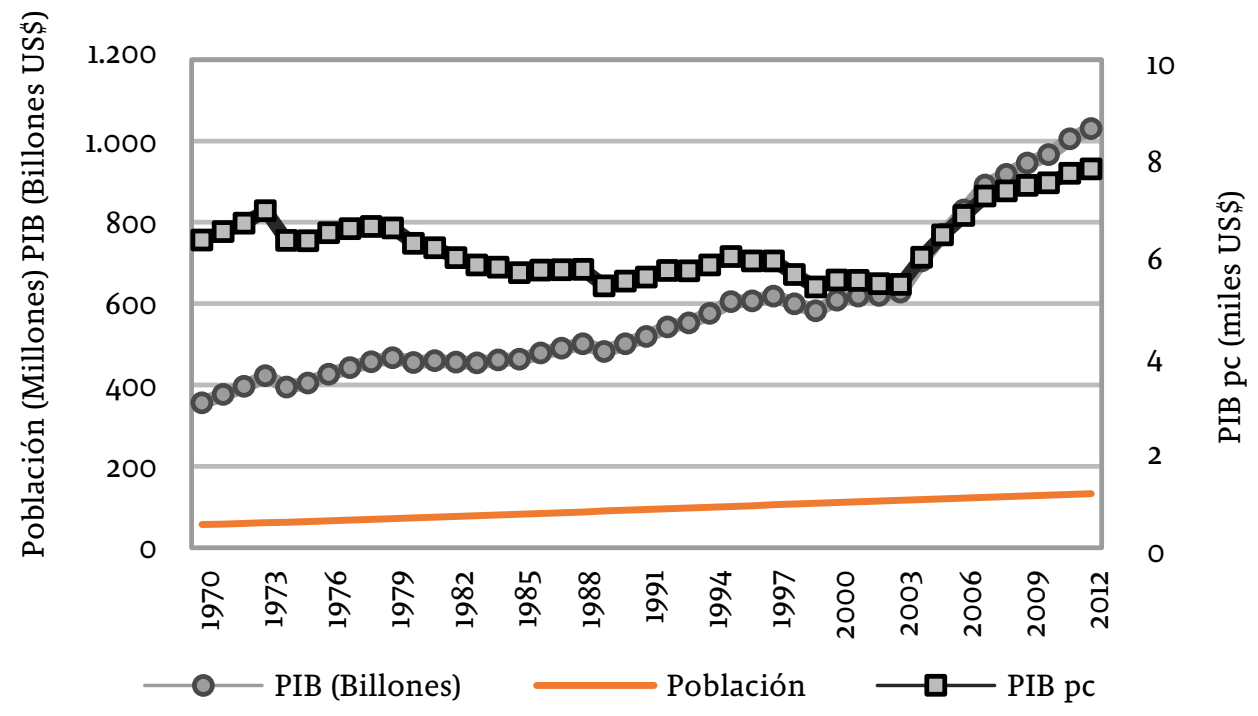

Fuente: Feenstra, Robert y Timmer (2013); Celade (2014). 
Figura 3. Estructura del PIB en dinero

Región Andina (1990-2014). Porcentaje del PIB precios corrientes.

Estructura sectorial del PIB países andinos (1990 - 2014)

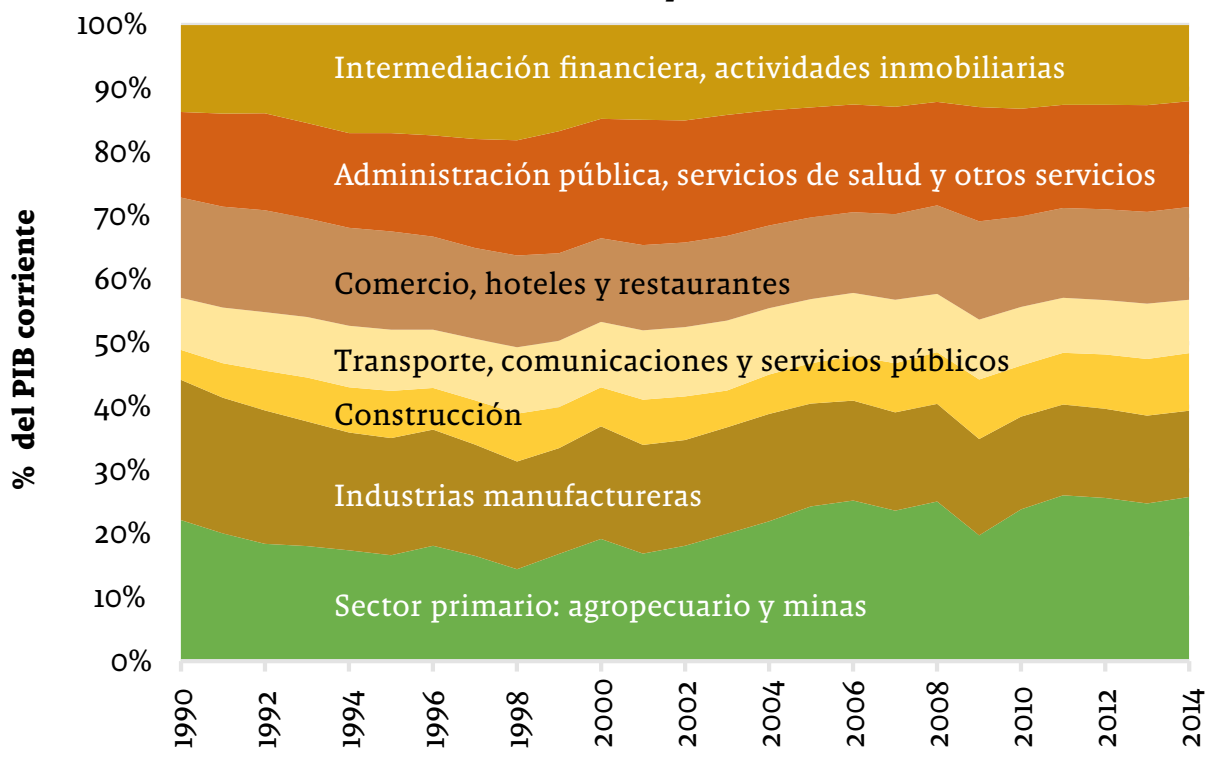

Fuente: Cepal (2015b).

Figura 4. Tendencias económicas y demográficas

Región Centroamericana (1970-2012). Producto interno bruto (PIB) medido en dólares a precios constantes (2005) con PPA.

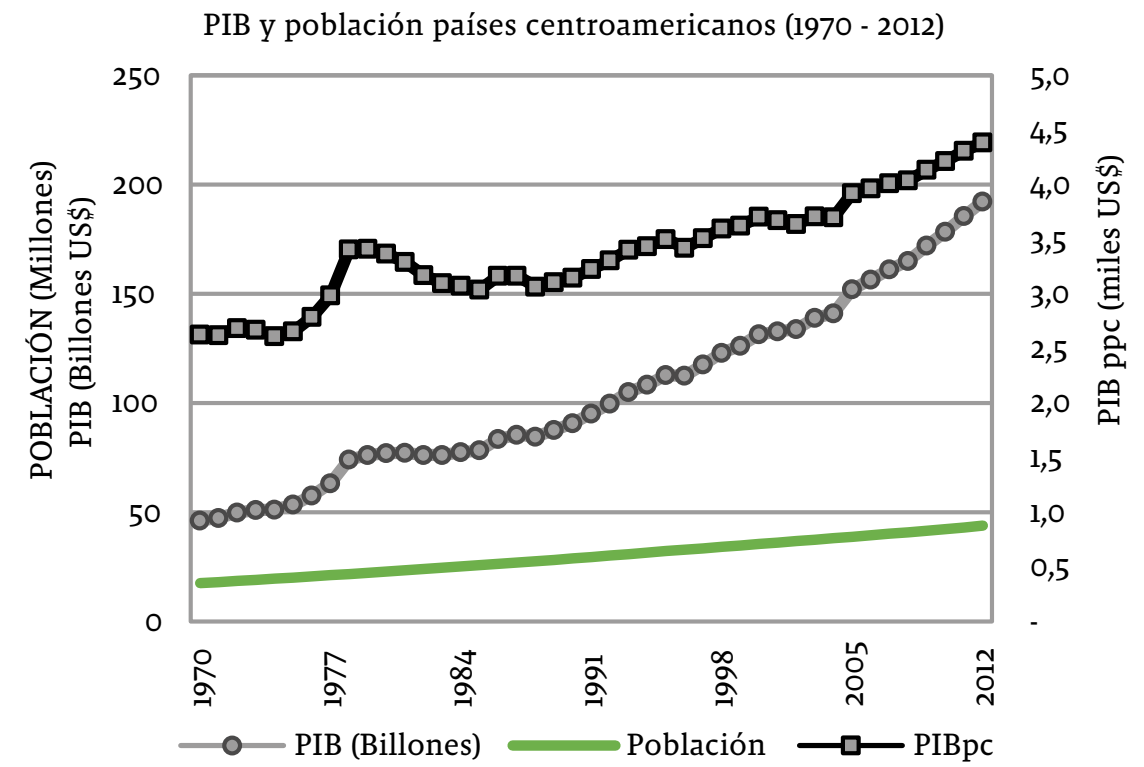

Fuente: Feenstra, Robert y Timmer (2013); Celade (2014). 


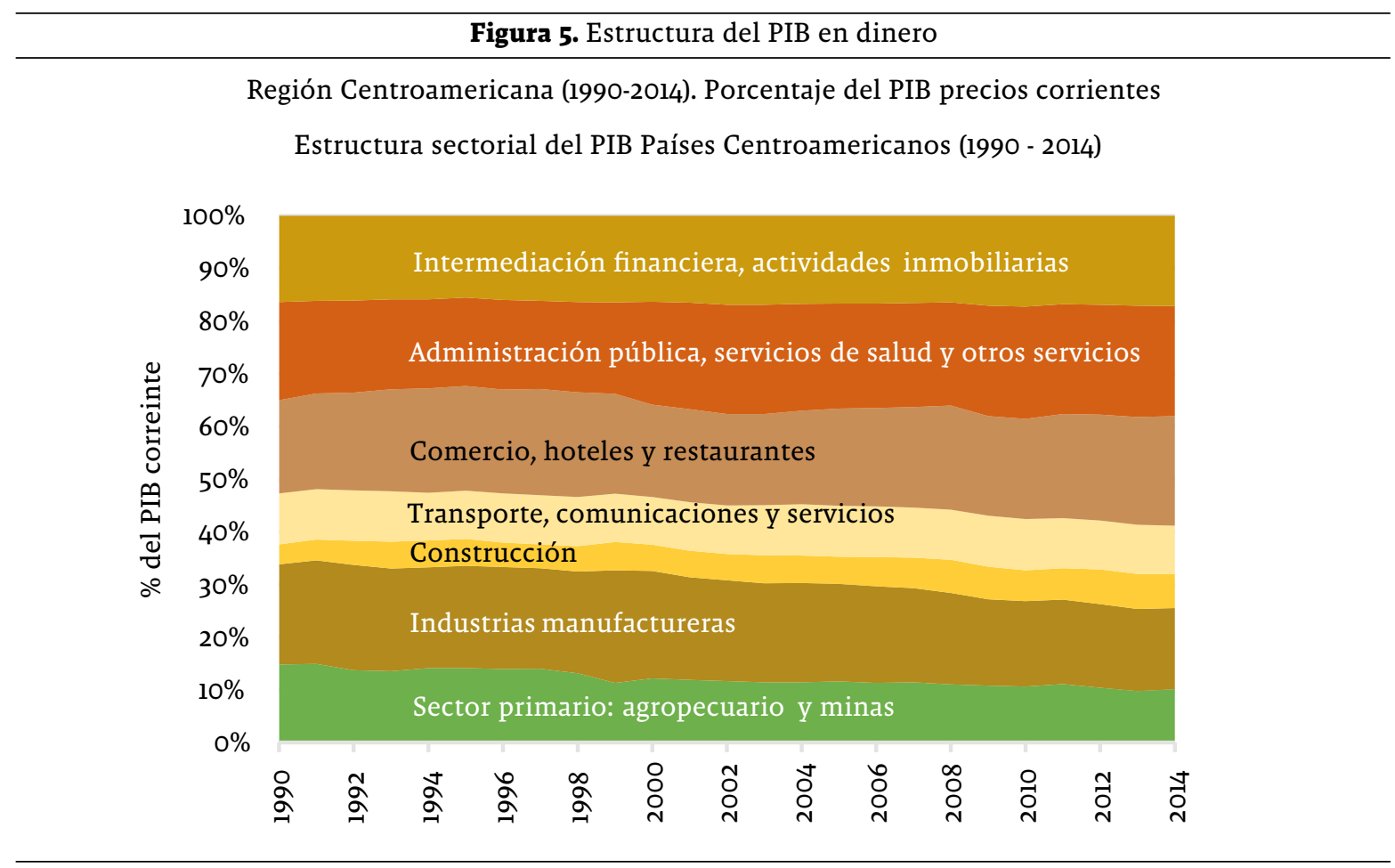

Fuente: Cepal (2015b).

PIB per cápita, el andino ha sido siempre más alto que el centroamericano; sin embargo, esta diferencia se ha venido reduciendo paulatinamente: en 1970 los países andinos tenían un ingreso per cápita promedio de US\$6.300 frente a US\$2.626 en Centroamérica, es decir 2,4 veces superior. En 2012, este diferencial se redujo a 1,8 veces (US\$7.757 versus US\$4.387).

En la dinámica de la estructura económica que compone el PIB también existen importantes diferencias: en la región Andina el sector primario ha ganado participación, la industria ha perdido peso en forma acentuada y el sector terciario disminuyó ligeramente (1\%). En Centroamérica, el sector extractivo disminuyó su importancia, mostrando que no se puede hablar de reprimarización en todo el subcontinente latinoamericano; el sector manufacturero cayó, pero en menor proporción; y el sector servicios incrementó en 5 puntos porcentuales su participación.

\section{Resultados en términos de perfiles metabólicos \\ 4.1. Insumo directo de material (DMI) $^{15}$}

El perfil metabólico de un país o región se define por el nivel y estructura del uso de materiales. En relación con la estructura es importante diferenciar entre dos grandes bloques: el componente biótico y el abiótico. El primero corresponde a la biomasa agrícola, forestal y pesquera y el segundo a los combustibles fósiles, los minerales metálicos, industriales y de construcción. Cuando un país se especializa en la producción de componentes bióticos significa que tiene un perfil metabólico asociado a un régimen agropecuario; cuando se especializa en el sector minero-energético hay dos opciones:

15 Mientras la información para DMI y DMC va hasta 2012, la información para PTB se extiende hasta 2013. Esto por no encontrarse para todos los países alguna información requerida para construir la serie hasta 2013. 
i) si la extracción se dirige al mercado interno, significa que tiene una transición hacia un régimen urbano-industrial; ii) si se orienta hacia el mercado externo, esta transición no es tan clara y por el contrario puede caracterizar una economía de enclave primario-exportadora con pocos escalonamientos hacia atrás y hacia delante en el mercado interno, cayendo en trampas de especialización: hacia sectores intensivos en el uso de la naturaleza y en contaminación, y poco generadores de valor agregado.

La Figura 6a y la Figura 6b muestra el DMI de las dos regiones analizadas, detallando cada una de las categorías de extracción doméstica y las importaciones. En el período estudiado el DMI en la región Andina pasó de 641 millones de toneladas (MT) a 1.602 MT, es decir, creció a una tasa de 2,2\% promedio anual. En el caso de Centroamérica, el indicador pasó de $96 \mathrm{MT}$ a 352 MT, creciendo a una tasa de 3,1\% anual, mostrando así, una mayor dinámica material en relación con la economía andina.

Respecto a la estructura del DMI, se observa que la mayor parte la conforma la extracción doméstica. Pese a que las cuotas de importación se han incrementado desde 1991 con la liberalización económica, estas siguen siendo irrelevantes en proporción al DMI total. Mientras en 1970 la participación de las importaciones en el DMI era de $1,3 \%$ en los Andes y 4,2\% en Centroamérica, en 2012 estas subieron ligeramente a $5,3 \%$ y $8,5 \%$ respectivamente; mostrando un mayor consumo material del exterior en Centroamérica que en la región Andina. En ambos casos se evidencia que no existe dependencia material externa; ambas economías proveen el material requerido para su funcionamiento, lo que es propio de los países en desarrollo que desempeñan el papel de abastecedores de recursos materiales para el funcionamiento metabólico de la economía global.

La extracción doméstica de la región Andina cambió su estructura interna en el período evaluado (Figura 6a). El sector biótico que en 1970 ocupaba $41 \%$ de la participación de la extracción, en 2012 descendió a $28 \%$ en su participación, explicado por una caída de la biomasa forestal, pesquera y de pastoreo. Es de resaltar que los cultivos primarios mantienen su participación a lo largo del período en un promedio de $9 \%$ por ser la base de nutrientes para el consumo humano y la producción de algunas materias primas para la industria. Sin embargo, la participación de los bienes agrícolas para consumo humano ha sido desplazada por bienes agrícolas para la industria como la soja, la caña de azúcar, la quinua, los espárragos y la palma aceitera. Contrastando con esto, el sector abiótico incrementó su participación de $59 \%$ a $72 \%$, de lo que se infiere una tendencia a la especialización material abiótica. El componente de mayor crecimiento fueron los minerales, al pasar de $24 \%$ en 1970 a $46 \%$ en 2012 , explicado principalmente por los minerales metálicos y los de construcción, que se duplicaron, ocupando en $201222 \%$ y $24 \%$ respectivamente. La extracción de combustibles fósiles (petróleo, gas y carbón), explicada en buena medida por Venezuela, Colombia y Ecuador, muestra una caída en la participación de $35 \%$ a $26 \%$. Aunque en términos absolutos casi se vio duplicada al pasar de 219 MT a 398 MT.

La caída del peso de los combustibles fósiles se explica por el comportamiento de Venezuela que redujo su dinámica petrolera de $195 \mathrm{MT}$ en 1970 (66\% de su DE) a 187 MT (50\% de su DE) en 2012. Situación contraria se dio en Ecuador al pasar de 1 MT (o,8\% de su DE) a 27 MT (20\% de su DE) en el mismo período, explicada por un fuerte incremento en la extracción de petróleo. De manera similar ocurrió en Colombia donde la extracción fósil pasó de 16 MT en 1970 (12\% de su DE) a 152 MT (33\% de su DE) en 2012, aumento explicado principalmente por la extracción de carbón. Los resultados anteriores muestran a primera vista una región Andina cuyos patrones extractivos aparentemente obedecen a una transición hacia un régimen urbano-industrial, centrado en la explotación de combustibles fósiles, hierro y otros minerales no ferrosos como el oro, la plata, el cobre y el zinc. Sin embargo, esta realidad será contrastada más adelante con el patrón exportador, para obtener una conclusión acertada. 
Figura 6. Insumo directo de material (DMI) de las regiones Andina y Centroamericana, 1970-2012 (toneladas)

a) Región Andina

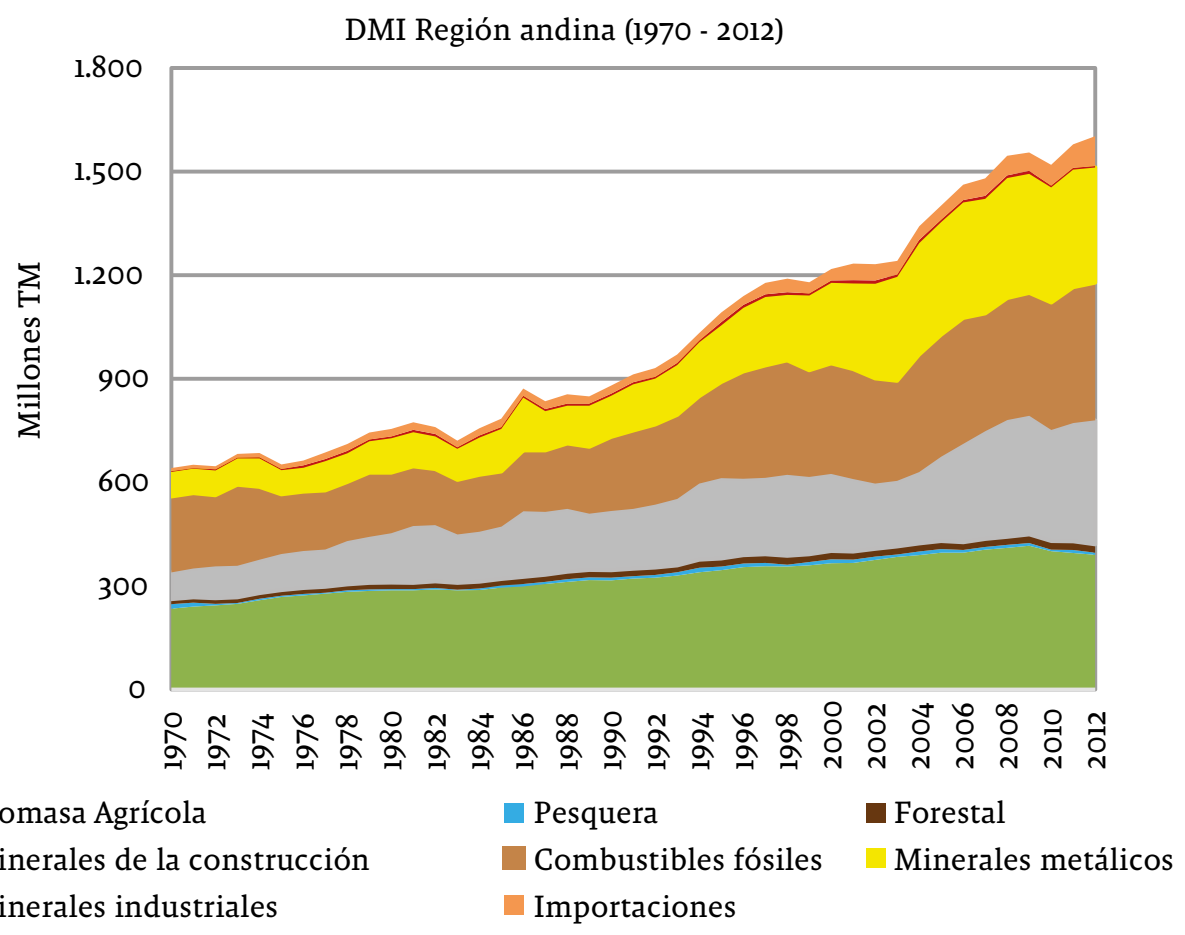

b) Región Centroamericana

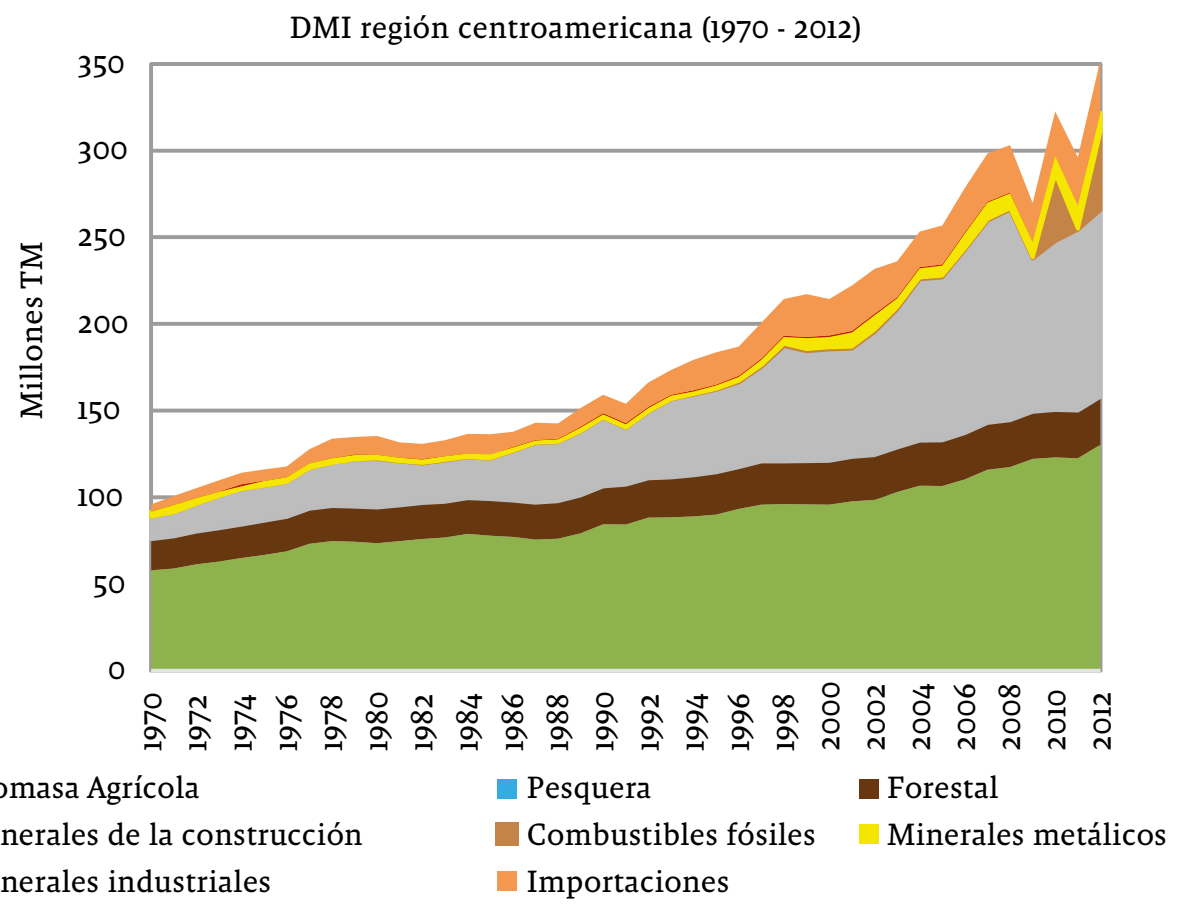

Fuente: Cepal (2015b). 
Por su parte, la estructura de la extracción centroamericana revela un importante descenso del peso de la biomasa, pasando de $83 \%$ a $49 \%$ entre 1970 y 2012 (Figura 6b). Esto se debe a que las tasas de crecimiento de los materiales abióticos han sido elevadas y han desplazado la participación biótica en la economía, contrario a lo evidenciado en el aspecto crematístico de la caracterización socio-económica. Los componentes que explican la caída de la biomasa son la actividad forestal y la biomasa de pastoreo.

Los minerales metálicos y los materiales de construcción fueron las categorías de mayor crecimiento del sector abiótico en Centroamérica. Los minerales metálicos ferrosos crecieron a una tasa de $9 \%$ anual y los no ferrosos, de $3 \%$; sin embargo, el peso de ambos en la extracción total sigue siendo bajo, $3 \%$ y $0,3 \%$, en el mismo orden. Los materiales de construcción son la segunda categoría de mayor peso después de la biomasa agrícola, con $33 \%$ en 2012. En este año, la producción de cemento per cápita fue de $280 \mathrm{~kg} / \mathrm{hab}$, siendo los principales productores Panamá, Costa Rica y El Salvador, donde están presentes dos de las multinacionales más grandes de este sector, Holcim y Cemex (Ficem, 2013). Lo anterior puede estar relacionado con tres fenómenos complementarios: i) el proceso de urbanización, que se incrementó de $39 \%$ a $60 \%$ en el período 1970-2010; ii) este fenómeno se acompañó con la reconstrucción de varios países centroamericanos afectados por el Huracán Mitch ocurrido a finales de 1998; iii) el desarrollo de grandes obras públicas, en particular la ampliación del canal de Panamá que se inició en 2007. La participación de los combustibles fósiles en Centroamérica es despreciable. Sin analizar el sector externo, los resultados anteriores muestran una región que mantiene unos patrones de desarrollo material de tipo rural evidenciados por el peso de la biomasa tanto agrícola como forestal, que hace una transición lenta hacia un régimen urbano-industrial (ver transiciones socio-ecológicas en Krausmann, Fischer-Kowalski, Schandl y Eisenmenger, 2008, p. 643).

\subsection{Consumo doméstico de materiales (DMC)}

El DMC andino aumentó de 414 MT a 1.319 MT entre 1970 y 2012; es decir, creció a una tasa promedio anual de 2,8\%. En la región Centroamericana el
DMC aumentó de 92 a 392 MT para el mismo período, mostrando un mayor crecimiento $(3,1 \%$ anual) en relación con la región Andina. El anterior comportamiento reduce el diferencial de ambas economías en términos de consumo material: mientras en 1970 la economía andina era 4,5 veces superior a la centroamericana; en 2012, esta relación se redujo a 3,4 veces (Figura 7a, Figura 7b).

La estructura de consumo doméstico o interno de material muestra para la región Andina que sus mayores componentes en 2012 y sus porcentajes son la biomasa agrícola, 31\%; los materiales de construcción, 28\%; los minerales metálicos, $26 \%$ y los combustibles fósiles, $13 \%$. En el caso de la biomasa y los minerales de construcción buena parte de lo que se extrae es para consumo interno. Diferente ocurre con los combustibles fósiles y los minerales metálicos. En 2012, por ejemplo, de 370 MT extraídas de combustibles solo 173 MT fueron consumidas por la economía de la región, lo que indica un consumo equivalente a $47 \%$ de lo extraído. El resto se comercializa en el mercado externo, principalmente hacia Estados Unidos (Cepal, 2015b). En el caso de los minerales metálicos se registraron en 2012, 334 MT de extracción, frente a un consumo interno de 335 MT; esta igualdad entre ambas variables es aparente, pues el DMC se sobreestima al no registrarse en las exportaciones todo el material de relave que necesariamente se debe extraer para obtener cada tonelada de mineral contenido ${ }^{16}$.

En la región Centroamericana, la estructura de consumo doméstico muestra tres componentes principales en 2012: la biomasa agrícola que tiene un peso de 38\%; los materiales de construcción de $32 \%$ y la biomasa forestal de $9 \%$. Una de las razones que explican la realidad constructora de la región es el comportamiento de Panamá que

16 Puesto que DMC = DMI - X, entonces, una subestimación de $\mathrm{X}$ aumenta el DMC. La subestimación de las exportaciones $(\mathrm{X})$ está dada porque en las bases de datos de Comtrade, los flujos de comercio de los minerales metálicos con bajo procesamiento se registran como mineral contenido en la roca mineralizada y lo demás, calificado como relave, queda por fuera de la contabilidad por no poseer un valor económico. Por el contrario, en las cifras calculadas para la extracción doméstica (DE) se incluye tanto el mineral contenido como el relave. Esto lleva a que el consumo de este tipo de material parezca mayor al valor real (ver terminología de minerales, Eurostat, 2013). 
Figura 7. Consumo doméstico de materiales (DMC) de las regiones Andina y Centroamericana, 1970-2012 (toneladas)

a) Región Andina

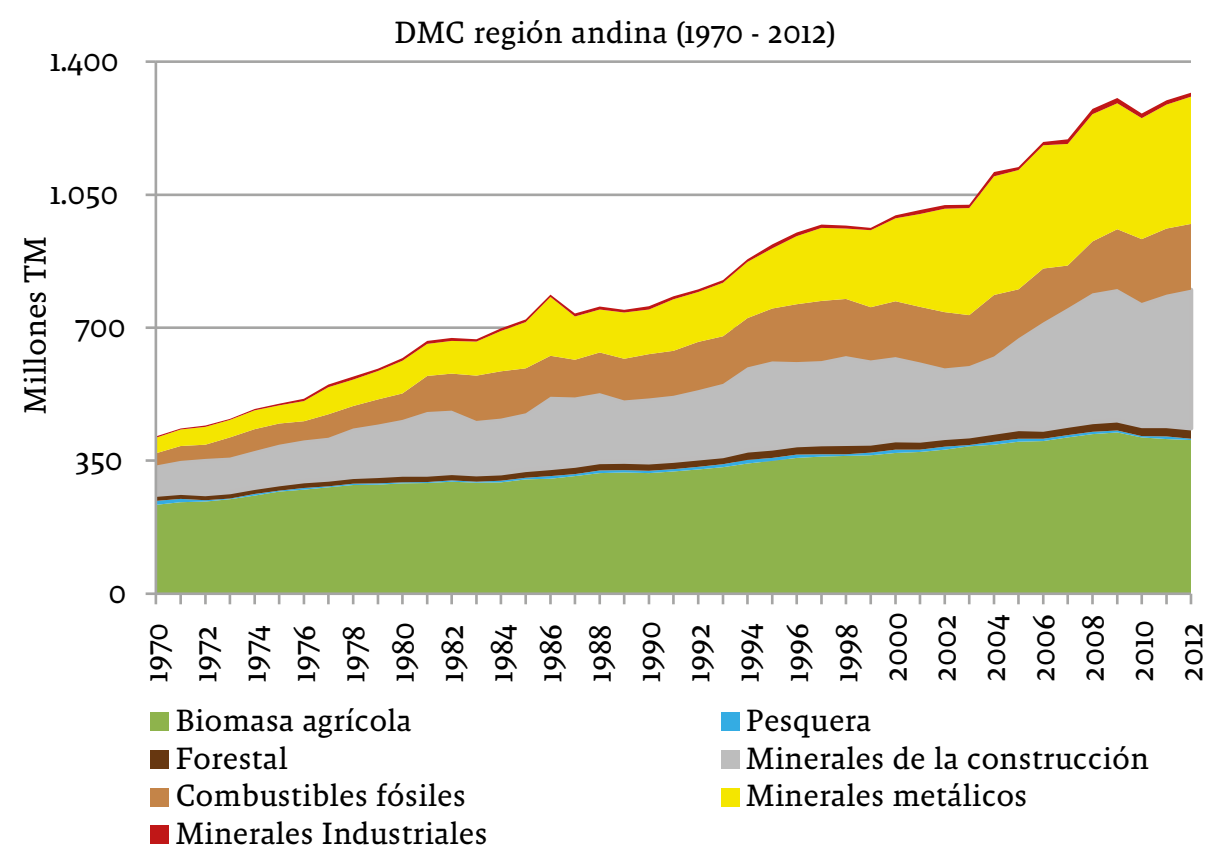

b) Región Centroamericana

DMC región centroamericana (1970 - 2012)

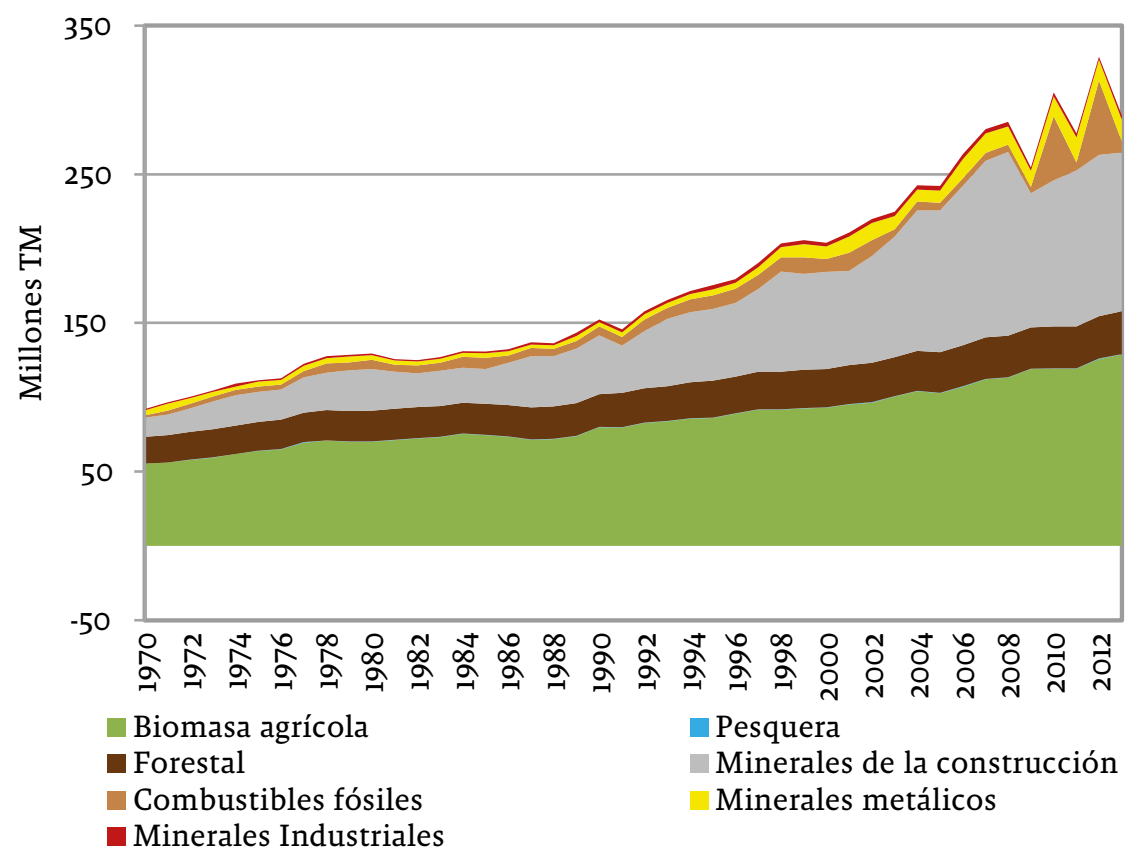

Fuente: Elaboración propia. 
es el país de mayor consumo per cápita de cemento en Latinoamérica: $644 \mathrm{~kg} / \mathrm{hab}$ frente a 301 $\mathrm{kg} / \mathrm{hab}$, para el promedio. Esto tiene relación con la inversión estatal en obras de infraestructura como la ampliación del canal, el metro, la modernización de la red vial, entre otros (Ficem, 2013). La estructura del DMI y el DMC en la región son similares, puesto que los niveles de exportación son bajos, alcanzando estos tan solo $7 \%$ de los insumos materiales (DMI).

En síntesis, desde el punto de vista del consumo, ambas economías evidencian un determinado perfil metabólico. La economía andina, con una estructura de consumo de $33 \%$ de material biótico y $67 \%$ abiótico, donde se destaca la construcción (28\%), evidencia una transición hacia un régimen urbano-industrial. Por su parte, Centroamérica, con un consumo de $47 \%$ de material biótico y $53 \%$ de material abiótico en 2012 , tiene una mayor base agropecuaria en relación con la región Andina y asimismo puede considerarse, desde la perspectiva del consumo, como una economía con una transición lenta hacia un patrón urbano-industrial.

\subsection{Balanza comercial biofísica (PTB)}

El intercambio ecológicamente desigual se define a partir de las asimetrías en el comercio internacional que prevalecen entre las llamadas economías del Norte (países desarrollados) y las del Sur (países en desarrollo). Muchas economías del Sur tienen una salida neta de materiales $(X)$ M) para cubrir la demanda externa de las economías del Norte, cuyo funcionamiento metabólico depende de estas fuentes de recursos (Hornborg, 2012; Pérez-Rincón, 2006). El material exportado por el Sur se obtiene a partir de procesos extractivos que deterioran la base ecosistémica y generan presiones ambientales, dado el alto peso de sus exportaciones primarias. En este escenario, el comercio internacional desempeña un papel protagónico como un nuevo "vector ambiental" (Karlson, 1995) (igual que el aire, el agua y el suelo), que distribuye en forma diferente los costos ecológicos entre los países que comercian. Desde esta perspectiva, el comercio internacional no es un juego de suma positiva donde todos los participantes resultan ganadores por el intercambio comercial, sino que es un juego de suma cero, donde hay beneficiados y afectados en los aspectos ecológicos, incluso de suma negativa si incluimos la entropía (Pérez-Rincón, 2008).

De manera que si la balanza comercial biofísica es negativa ${ }^{17}(X>M)$, significa que el país es un exportador neto de materiales, evidenciando la presión del consumo externo sobre el espacio ambiental de un país o una región, siendo además un indicativo de la deuda ecológica que el resto del mundo tiene con este territorio. Por el contrario, en el caso que las importaciones sean mayores a las exportaciones biofísicas, se muestra que para satisfacer su consumo material interno, requiere importar de otros países. El primer caso corresponde a la región Andina, la cual presenta un déficit permanente en la balanza comercial biofísica, déficit que se ha venido incrementando a lo largo del período estudiado: pasó de $218 \mathrm{MT}$ en 1970 a $230 \mathrm{MT}$ en 2013 (Figura 8a). Como lo menciona Vallejo (2015), estos recursos que provienen del exceso de exportaciones, se obtienen mediante procesos extractivos que afectan el medio ambiente e introducen presiones sobre los recursos domésticos, en beneficio de los consumidores de otros países. Este déficit se ha incrementado desde mediados de la década de 1980 con las políticas de apertura comercial.

La balanza monetaria por su lado en la región Andina (Figura 9a), tiene una tendencia decreciente hasta 1998, siendo deficitaria durante casi 10 años (1989-1998). Este comportamiento puede atribuirse a la baja en los precios internacionales del principal producto exportado, el petróleo crudo. De acuerdo con la información ofrecida por el Banco Mundial (2015) sobre los precios de las commodities, el precio promedio del petróleo crudo bajó desde 1986 y solo se recuperó en 1998. De igual forma, el superávit comercial financiero a partir de los años de 1990 se explica por el aumento de los

17 La balanza comercial biofísica se lee contrario a la monetaria: cuando es deficitaria, las exportaciones son mayores que las importaciones, cuando es superavitaria la situación es la contraria. 
precios internacionales del petróleo, el carbón, el gas natural y los minerales. Aunque no es parte del período de análisis, cabe anotar que el descenso del precio de las commodities a partir de 2013 hizo que desde 2014 la balanza comercial monetaria de estos países volviera a ser de nuevo deficitaria, acentuando la trampa de especialización: mayor presión sobre el ambiente y menos recursos externos para atenuar en algo los impactos ambientales y sociales de los territorios exportadores, paradoja reportada por Samaniego, Vallejo y Martínez-Alier (2017).

La balanza comercial biofísica centroamericana, por el contrario, se mantiene positiva en todo el período analizado, alcanzando el punto máximo en 2001 con 15 MT (Figura 9b). Esto significa que para satisfacer una parte de su consumo material la región debe importar más material. Lo anterior explica en buena medida el balance monetario negativo durante casi todo el período, teniendo que sacar divisas en forma creciente para satisfacer su consumo doméstico. Al final del período (2013), el déficit financiero alcanzó $14.504 \mathrm{mi}$ llones de dólares, frente a un superávit biofísico de 9 MT.

Cuando se examina la estructura del comercio exterior, se encuentra que los países andinos se especializan en la exportación de recursos no renovables (energía fósil y minerales metálicos) para satisfacer el proceso metabólico de los países desarrollados (Figura 9a). Particularmente Perú y Venezuela han tenido como columna vertebral de su economía la explotación de recursos no renovables desde antes de 1970. Para el caso colombiano, este patrón adquirió peso a partir de 1985 a través de los combustibles fósiles con los descubrimientos en el país de petróleo en Cusiana y Cupiagua en el oriente y de carbón en El Cerrejón y La Loma en el norte; a partir de ello, actualmente la exportación biofísica de combustibles fósiles colombiana es superior a los niveles de exportación de energía fósil venezolana. Las políticas de desarrollo económico de los países andinos centradas en la extracción de minerales y combustibles, desde el 2000, han desplazado incluso la producción agrícola, hasta el punto que desde la mitad de la década de 1990 aparece un superávit neto en la balanza comercial biofísica de alimentos para la región, es decir, se importa más comida de la que se exporta, lo cual afecta la soberanía y seguridad alimentaria de estos países (Figura 9a). Por su parte, el análisis del comercio andino por niveles de procesamiento, muestra un aumento de la reprimarización ${ }^{18}$ : mientras en 1970 las exportaciones físicas de bienes primarios ocupaban $74 \%$ del total de exportaciones, en 2013 habían crecido a $88 \%$ (Pérez-Rincón, 2016).

La estructura de la balanza comercial biofísica centroamericana muestra una situación contraria a la andina, caracterizándose por un superávit permanente $(\mathrm{M}>\mathrm{X})$. En Centroamérica, mientras las exportaciones netas corresponden casi exclusivamente a biomasa, las importaciones son más diversificadas y en mayores cantidades: combustibles fósiles y minerales metálicos, industriales y de la construcción (Figura 9b). Dada la magnitud de las importaciones, se genera una balanza biofísica positiva significando que la región Centroamericana trasfiere costos ambientales hacia otros países. Sin embargo, se requiere hacer el balance entre la carga ambiental de las importaciones (minerales y combustibles fósiles) frente a los costos ambientales de las exportaciones (biomasa) para obtener una conclusión más precisa al respecto.

Respecto al nivel de procesamiento en Centroamérica, las exportaciones de bienes finales registraron un cambio en su participación, de $37 \%$ en 1970 a $42 \%$ en 2013 ; es decir, aumentó la venta al exterior de productos con mayor valor agregado, explicado en buena parte por la maquila de ropa y confecciones hacia

18 Reprimarización es la reorientación de los recursos de una economía, o de su perfil productivo, hacia actividades con reducido contenido de valor agregado, predominantemente las primario-extractivas, incluyendo la actividad de ensamblaje y otros procesos industriales con escasa utilización de conocimientos (Nadal, 2011; Slipak, 2012). 
Figura 8. Balance comercial físico y monetario de las regiones andina y centroamericana, 1970-2013 (toneladas)

a) Región Andina

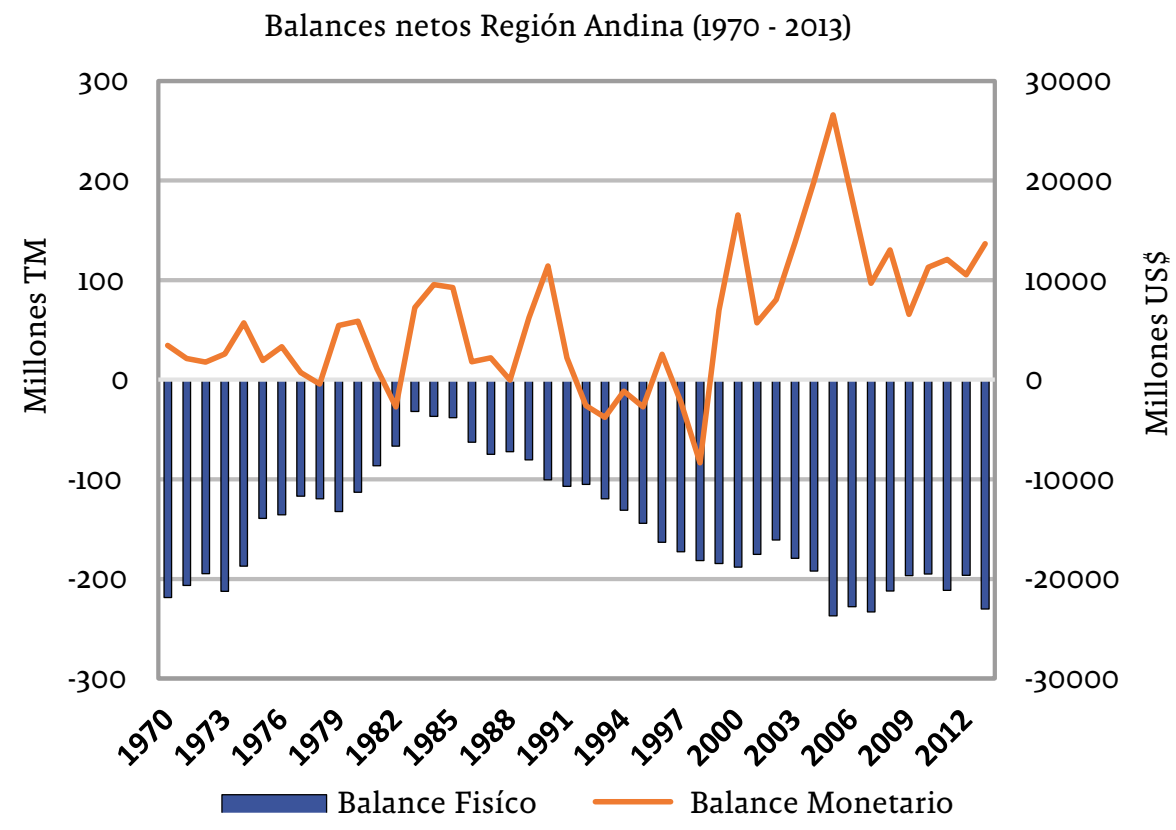

b) Región Centroamericana

Balances netos región centroamericana (1970 - 2013)

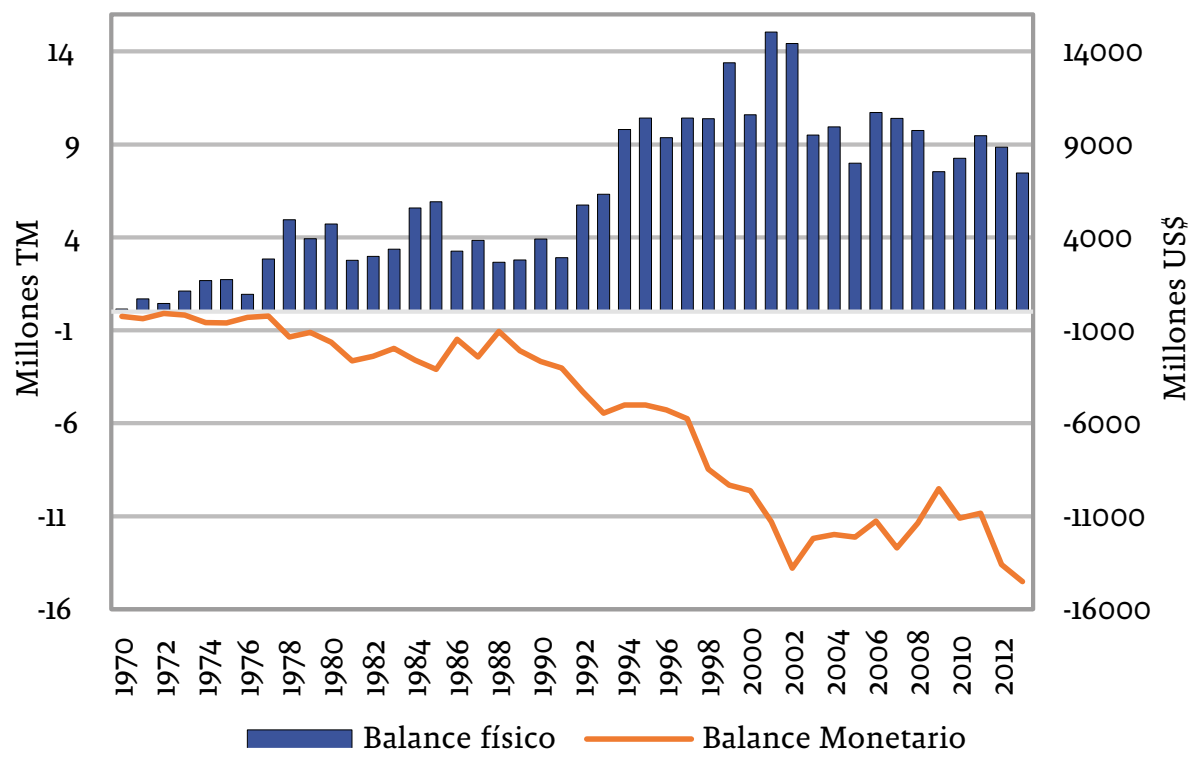

Fuente: elaboración propia. 
Figura 9. Balance comercial neto de las regiones andina y centroamericana, 1970-2013 (toneladas). Se expresa el balance neto por tipo de material

a) Región Andina

Balance comercial neto Región Andina (1970 - 2013)

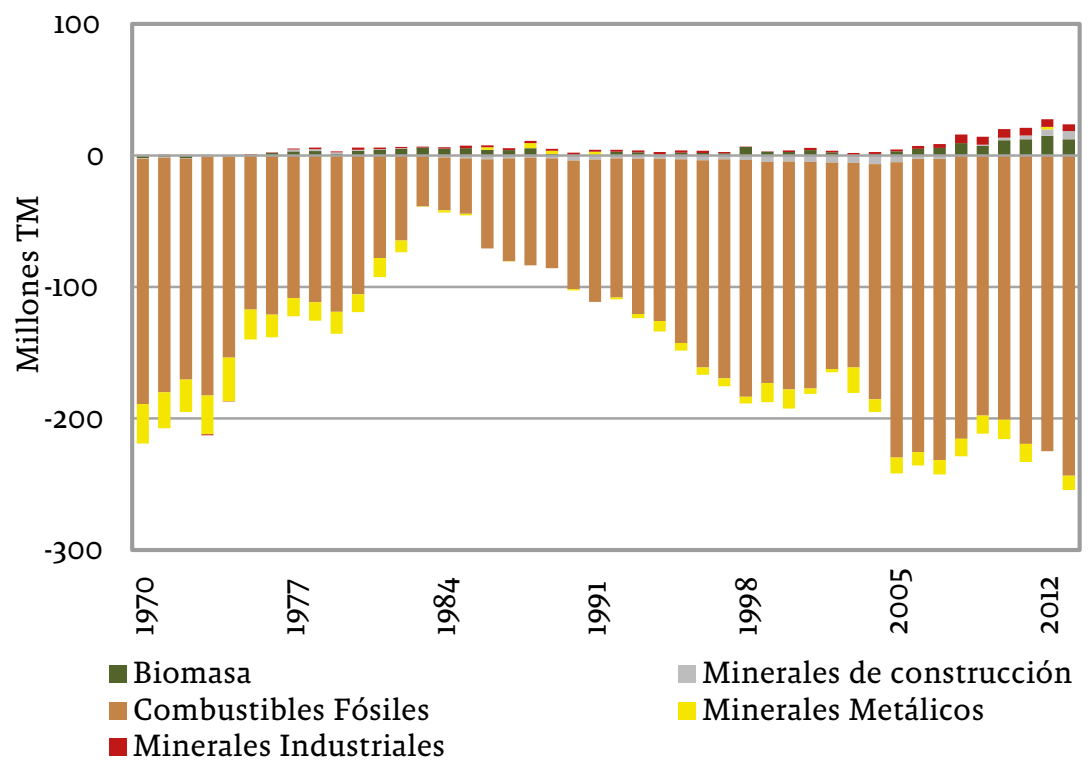

b) Región Centroamericana

Balance comercial neto Región Centroamericana (1970 - 2013)

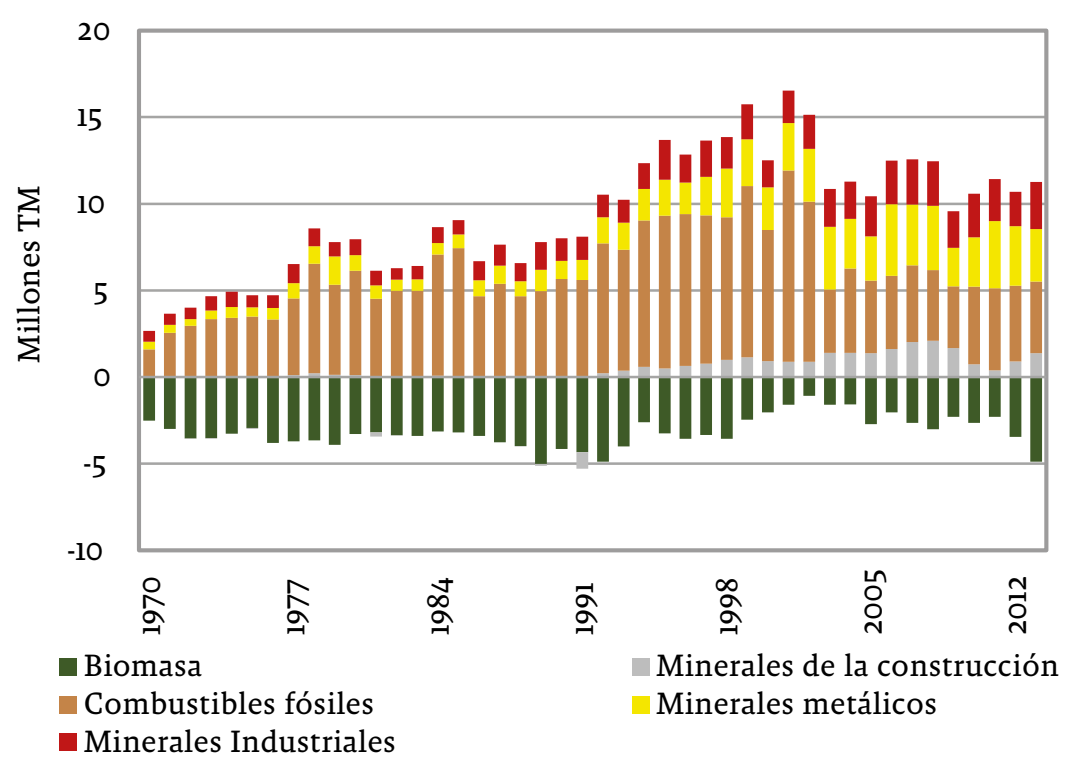

Fuente: elaboración propia. 
el mercado norteamericano. A pesar de ello, las exportaciones de bienes primarios continúan siendo superiores, donde sus principales productos exportados son los agrícolas: café, banano y azúcar evidenciando aún el perfil agrario de su economía (Cepal, 2015b).

Algunos autores (Bunker, 1985; Eisenmenger y Giljum, 2006) definen las economías extractivas como aquellas que se especializan en la extracción de recursos naturales para la exportación, relegando su consumo interno. En otras palabras, exportan una proporción significativa del total de materiales disponibles para el uso económico (X/DMI). Este último indicador debe ser superior al promedio mundial, que es $14 \%$, para ser considerada como extractiva (Krausmann et al., 2008). Aunque esta clasificación no está libre de críticas, se trata de una buena aproximación considerando la información que se halla disponible (Vallejo, 2015). En esa perspectiva, el indicador X/DMI alcanza para la región Andina un nivel de $18 \%$ en 2012 , lo que identifica su economía como de carácter extractivo; este indicador para Centroamérica es de $7 \%$ en el mismo año, lo que evidencia su carácter no extractivo.

\section{4. Índices intensivos de material}

En esta sección se compara el perfil metabólico de las economías estudiadas con la economía de la Unión Europea (UE-28 ${ }^{19}$ ), la cual, aunque tiene un tamaño territorial similar a la región Andina, tiene mayor población y mayor nivel de desarrollo. Así, mientras la población de la UE28 es de 505 millones de personas y su territorio de 4,5 millones de $\mathrm{km}^{2}$, su ingreso per cápita fue US\$30.041 en 2012. Por su parte, los países andinos tienen una población de 133 millones de personas, un área de 4,7 millones de $\mathrm{km}^{2} \mathrm{y}$ un ingreso per cápita US\$7.757 a 2012. La región Centroamericana de su lado cuenta con una población de 43,8 millones de habitantes, un área de 0,5 millones de $\mathrm{km}^{2}$ y un ingreso per cápita de US\$4.387. En una primera comparación por nivel de uso de materiales por persona (Figura 10a), con información para 2012, se observa

19 Incluye 28 países. mayor intensidad de extracción y uso de recursos naturales por parte de la Unión Europea, seguida de la región Andina y muy lejos de estas, Centroamérica. Sin embargo, buena parte del consumo doméstico de los europeos proviene de extraer recursos de otros países, evidenciado esto por el volumen de importaciones que alcanzaron 3,1 toneladas per cápita anual. Contrariamente, aunque los países andinos tienen una extracción doméstica similar a los europeos $(11,4$ $\mathrm{t} / \mathrm{hab}$ versus $11,6 \mathrm{t} / \mathrm{hab}$ ), su consumo doméstico es bastante inferior $(9,9 \mathrm{t} / \mathrm{hab}$ versus $13,5 \mathrm{t} / \mathrm{hab})$, explicado por los niveles de exportación de la región Andina: 2,2 toneladas por persona.

La región Centroamericana tiene una intensidad material per cápita bastante inferior a las otras dos regiones. Su extracción doméstica en 2012 es de $7,3 \mathrm{t} / \mathrm{hab}$, usada casi toda para consumir internamente, dado su bajo nivel de exportaciones per cápita: $0,6 \mathrm{t} / \mathrm{hab}$. Incluso, tiene un nivel de importaciones per cápita superior a las exportaciones, alcanzando 0,8 t/hab en 2012; acá se reitera una transferencia de costos ambientales desde Centroamérica a otros territorios, especialmente por recursos no renovables para el consumo de su población, pero definitivamente no al nivel de la Unión Europea.

Al comparar la intensidad material por área (Figura 10b), se identifica una diferencia significativa entre Europa y los países latinoamericanos: UE-28 supera a Centroamérica en dos veces y a los países andinos en cuatro veces. Así, mientras la UE-28 tiene un nivel de extracción doméstica que equivale a $1.303 \mathrm{t} / \mathrm{km}^{2}$, los países centroamericanos tienen una extracción de 645 $\mathrm{t} / \mathrm{km}^{2}$ y los andinos de $323 \mathrm{t} / \mathrm{km}^{2}$. En este gráfico se evidencia con claridad el papel del comercio exterior en aliviar la presión ambiental sobre el territorio europeo, trasladándole su carga ambiental a otros territorios de donde obtienen sus materiales. En este caso, al comparar el consumo doméstico (DMC) de la UE-28 con sus importaciones $(\mathrm{M})$, se observa que sus habitantes obtienen $23 \%$ de sus bienes materiales de consumo de territorio foráneo. Contrario al caso de América Latina, en particular los países andinos, donde la participación de las importaciones materiales en el 
Figura 10. Comparación de los flujos materiales per cápita y por intensidad de área, 2012

a) Flujos per cápita

Flujos de materiales per cápita 2012

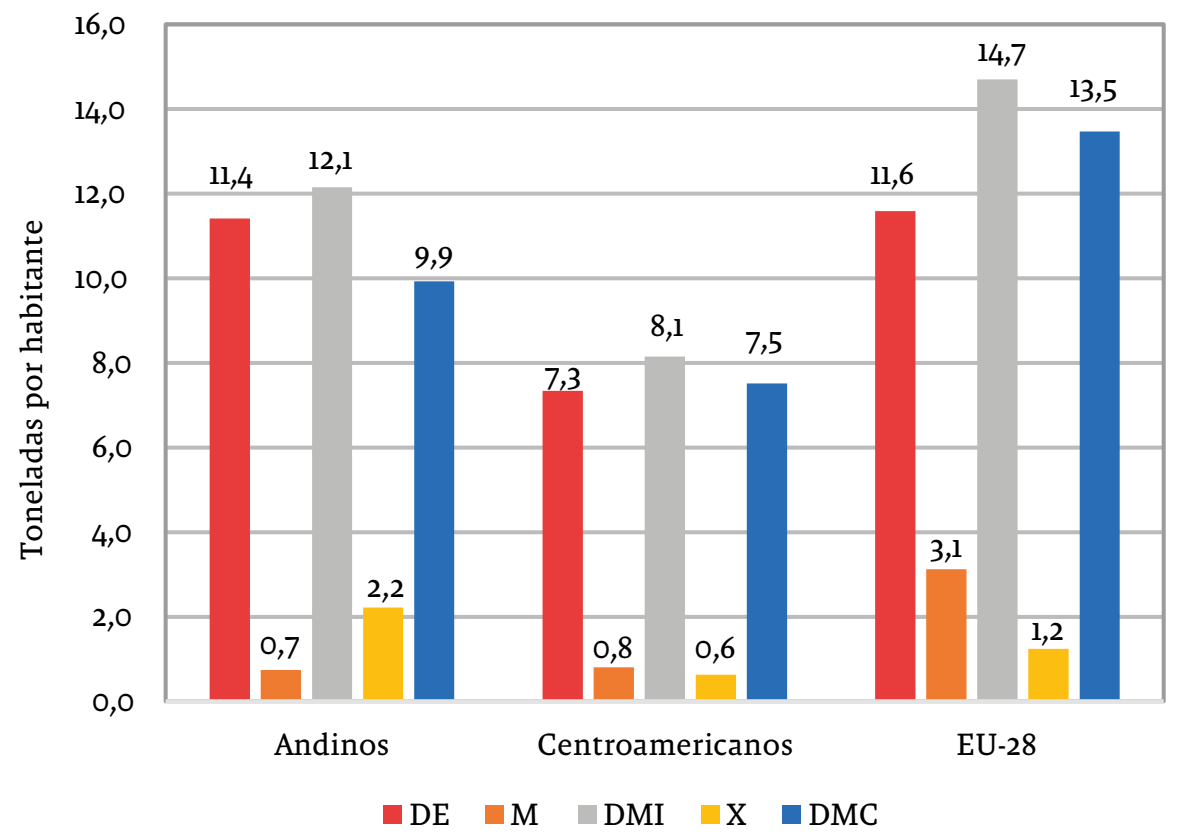

b) Flujos por $\mathrm{km}^{2}$

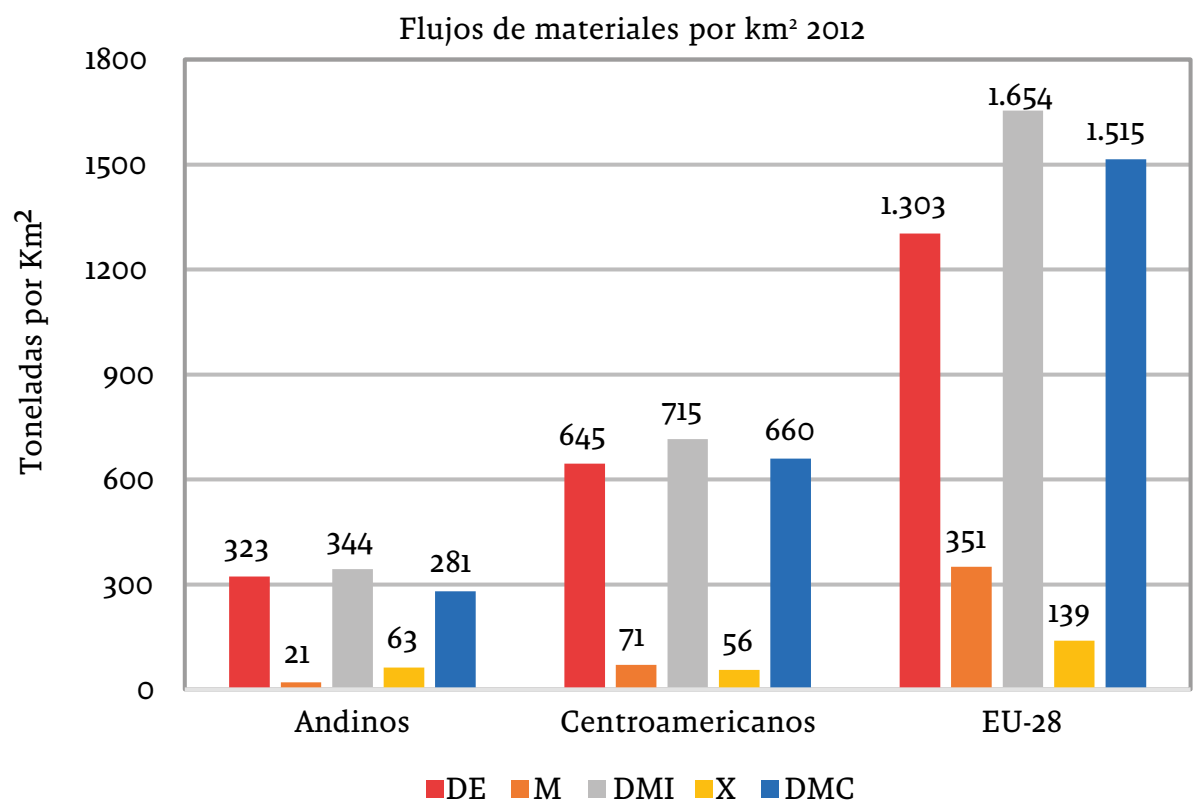

Fuente: elaboración propia y datos de la EU (Eurostat, 2015). 
consumo doméstico por $\mathrm{km}^{2}$ es de solo 7,5\%. Por su parte, aunque las importaciones $(\mathrm{M})$ en Centroamericana son más altas que las exportaciones $(\mathrm{X})$, su peso en el consumo interno además de ser menos intensivo $\left(71 \mathrm{t} / \mathrm{km}^{2}\right)$ que en UE-28, es también más bajo, alcanzando solo 10,8\% del mismo. Esto fortalece la evidencia de que, para satisfacer los niveles de consumo europeo, además de usar su territorio en forma más intensiva, trasladan su carga ambiental a otras regiones.

\subsection{Desacoplamiento y desmaterialización ambiental de las economías}

Cleveland y Ruth (1998) definen la desmaterialización como el proceso de satisfacción de las necesidades de la sociedad con un uso decreciente de materiales en el tiempo. De estos planteamientos surgen dos conceptos: la desmaterialización absoluta y la desmaterialización relativa. La primera se refiere a la disminución del material total incorporado durante el proceso económico y la segunda, conocida como desacoplamiento, apunta a un descenso en los requerimientos de energía y materiales por unidad de PIB (Carpintero, 2007; Riechmann, 2006; Vega, 2013).

En este contexto, corroboramos la hipótesis de materialización y de desacoplamiento de las economías de las regiones estudiadas. Por una parte, los resultados de los indicadores extensivos muestran clara evidencia de una materialización absoluta para las dos economías regionales tanto en términos del insumo directo de materiales (DMI) como del consumo doméstico de materiales (DMC). Esto señala una creciente presión de la economía sobre el espacio ambiental y sus ecosistemas en estas dos regiones.

Con relación al desacoplamiento (DMI/PIB), en la región Andina se observan dos tendencias: una primera, hasta principios del siglo XXI, donde hay un acoplamiento, pasando el DMI/PIB de 1,8 kg/US\$ a 2,03 kg/US\$ . Y una segunda, que paradójicamente se presenta a partir del inicio del boom mineroenergético 2000-2012 (decimos paradójicamente, puesto que es el período de mayor impacto ambiental en buena parte de la historia de los países andinos, producto del modelo neoextractivista que se ha venido impulsando desde 2000), donde se genera un desacoplamiento de las economías andinas respecto al DMI (Figura lia); este pasa de un índice de $2 \mathrm{~kg}$ por $1 \mathrm{US} \$$ generado a 1,6 kg. Este ciclo es explicado en buena medida por dos fenómenos relacionados: i) el crecimiento de los precios de las commodities que contribuyeron a aumentar el PIB nacional por el aumento de la participación del PIB extractivo. Y, ii) por la revaluación de las monedas nacionales hasta 2013 (a excepción de Ecuador cuya moneda es el dólar), que contribuyeron a aumentar el PIB en dólares. Evidencia del deterioro ecológico se halla en la creciente conflictividad ambiental de la región (EJatlas, 2017; Latorre, Farrell y MartínezAlier, 2015; Mesoca-Anca, 2016; Pérez, Sánchez y Zúñiga, 2014; Pérez-Rincón, 2016).

Sin embargo, este indicador de intensidad material que muestra la eficiencia ambiental de las economías, varía mucho de un país a otro dependiendo de sus patrones exportadores, sus ciclos económicos y el comportamiento de los precios. En el caso de Venezuela y Ecuador hubo acoplamiento desde 1970 hasta finales de 1990 , pasando de 1,6 a l,9 kg/US\$ en ambos países; a partir de allí se produce desacoplamiento llevando el indicador hasta 1,5 kg/US\$ en ambos casos en 2012. En Colombia, por el contrario, se da inicialmente un desacoplamiento desde 1970 hasta mediados de los de 1980; a partir de allí, se acopla la economía desde 1,14 hasta 1,26 kg/US\$ en 2012. En el caso de Perú, se identifican tres tendencias: primero desacoplamiento entre 1970 y 1998 pasando de $2,8 \mathrm{~kg} /$ US\$ a $2,2 \mathrm{~kg} / \mathrm{US} \$$; le sigue un período de acoplamiento hasta 2002 donde se alcanza 2,6 kg/US\$; luego, vuelve a desacoplarse ambientalmente la economía hasta 1,8 kg/US\$ en 2012. Finalmente, en Bolivia se da un acoplamiento desde 1970 (2,8 $\mathrm{kg} / \mathrm{US \$}$ ) hasta 1981 (4,6 kg/US\$) y desde allí se inicia un período de desacoplamiento hasta llegar en 2012 a $3,3 \mathrm{~kg} /$ US\$ .

En Centroamerica, se encuentran dos tendencias contrarias a las de los países andinos. Una primera, donde se produce desacoplamiento ambiental entre 1974 y 1992 , de $2,2 \mathrm{~kg} / \mathrm{US}$ \$ a $1,6 \mathrm{~kg} / \mathrm{US} \$$ en términos de DMI/PIB. Es decir hay una pérdida relativa de presión ambiental para producir una unidad de PIB en este lapso de 
Figura I.. Intensidad material de las regiones andina y centroamericana, 1970-2012

a) Región Andina

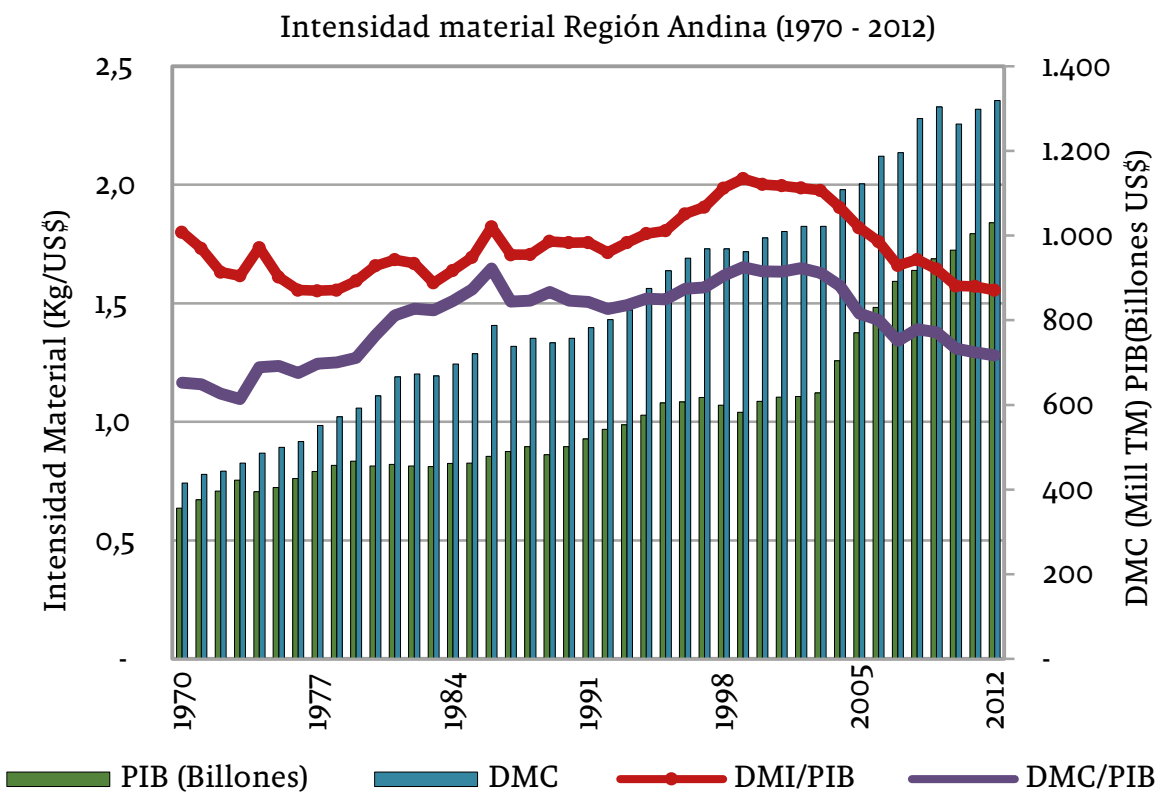

b) Región Centroamericana

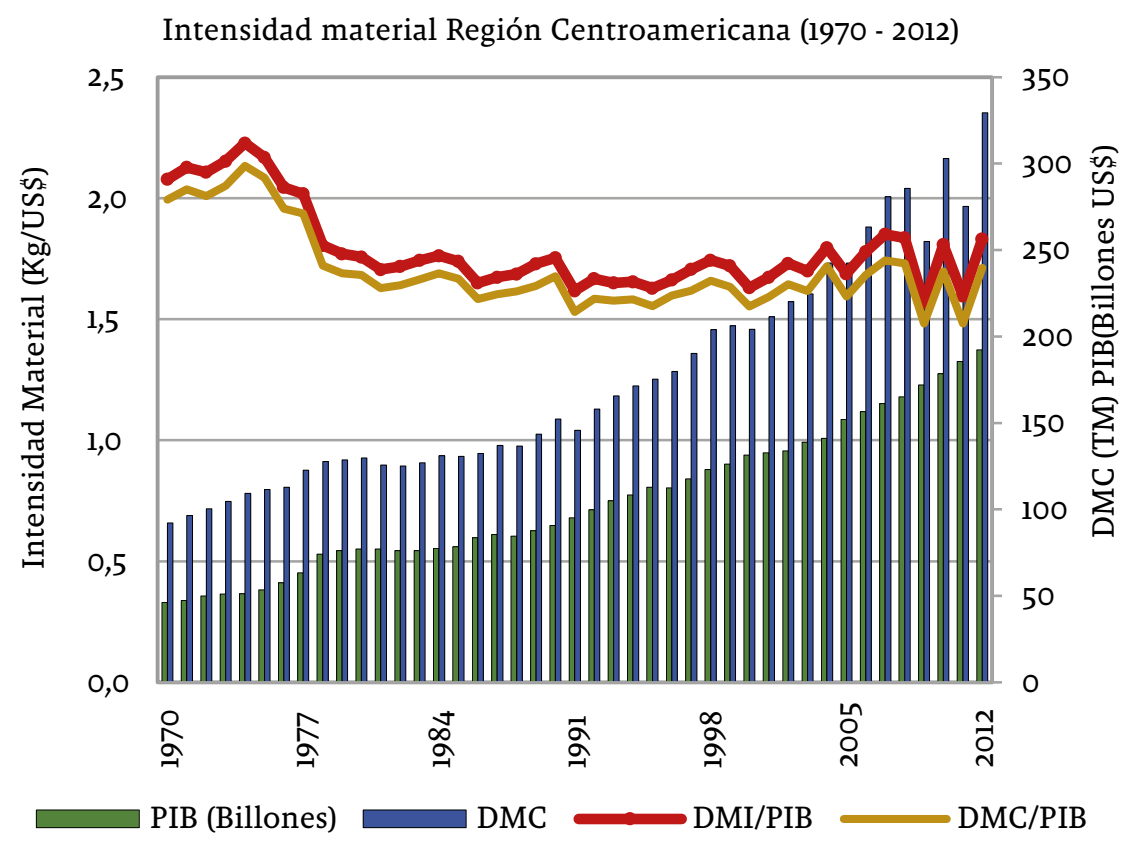

Fuente: elaboración propia. 
tiempo (figura llb). A partir de allí, se genera una tendencia ligera pero continua de acoplamiento que va desde 1,6 kg/US\$ hasta quedar en 1,8 kg/ US\$ en 2012. En suma, al comparar la intensidad material actual por unidad de PIB, Centroamérica es más intensiva en el uso de material que la región Andina: 1,8 kg/US\$ versus 1,6 kg/US\$ en 2012.

Con relación a cada país, los análisis arrojan que solo Costa Rica, Honduras y Panamá presentan una tendencia general al desacoplamiento en el período estudiado. Costa Rica inicia el período con un índice de $1,5 \mathrm{~kg} / \mathrm{US} \$$ y termina con $1 \mathrm{~kg} / \mathrm{US} \$$. Honduras en 1970 tiene un índice de 3,2 kg/US\$, cayendo en 2012 a 1,9 kg/US\$. En el caso de Panamá, se presenta el mejor resultado en términos de la disminución de la presión ambiental para producir una unidad de PIB comparando todos los países latinos analizados: pasó de $1,9 \mathrm{~kg} / \mathrm{US}$; a 0,8 kg/US\$ en 2012. Esto se explica por el importante papel del sector servicios en este país que incluye los subsectores de transporte (canal) y finanzas. El Salvador y Guatemala presentan un acoplamiento marcado desde 1970 hasta mediados de la primera década del 2000, pasando de 1,6 kg/US\$ y 1,2 kg/ US\$ respectivamente, hasta alcanzar $3,5 \mathrm{~kg} / \mathrm{US} \$$ y $2 \mathrm{~kg} / \mathrm{US}$ \$ cada uno en 2006. A partir de allí han experimentado un leve desacoplamiento. El Salvador alcanzó un indicador de 3,2 kg/US\$ y Guatemala de 1,6 kg/US\$ en 2012. Nicaragua presenta dos tendencias: la primera, un desacoplamiento que va de 2,6 a $1,7 \mathrm{~kg} / \mathrm{US} \$$ entre 1970 y 1987 y la segunda, un acoplamiento hasta 2012 donde alcanza 4,4 kg/US\$.

Sintetizando, se observa que las dos regiones aumentan las presiones sobre sus territorios y sus recursos naturales al analizar la materialización absoluta. Cuando se analiza el desacoplamiento se encuentran comportamientos disímiles. En el caso de los países andinos, la hipótesis de desacoplamiento no se cumple hasta inicios de la década del 2000. La situación en Centroamérica es contraria: hasta mediados de los años de 1990 hay desacoplamiento y a partir de allí hay un ligero acoplamiento material.

\section{Conclusiones}

Los datos encontrados muestran una intensa materialización absoluta en las dos economías regionales. Los resultados indican que a lo largo del período estudiado ambas regiones incrementaron el uso y extracción de recursos materiales, produciéndose lo que en el lenguaje de la economía ecológica y de la sustentabilidad se conoce como materialización absoluta. Así, mientras en la región Andina, el input material utilizado (DMI), se multiplicó por 2,5 veces (2,2\% de crecimiento anual); en el caso de Centroamérica, este indicador se multiplicó por 3,7 , con un crecimiento de $3,1 \%$ anual. Las categorías de mayor crecimiento en ambas regiones fueron los minerales metálicos y los minerales de construcción.

Las dinámicas económicas, las políticas nacionales y los contextos internacionales generan procesos de especialización productiva que cambian los perfiles metabólicos de los países con consecuencias ambientales. Tanto los países andinos como los centroamericanos cambiaron sus perfiles metabólicos en el período estudiado. En ambas regiones, su estructura metabólica es ahora más intensiva en materiales abióticos, perdiendo participación el componente biótico. Este cambio permite señalar que ambas regiones se encuentran en una transición urbano-industrial, más acentuada en la zona andina. Sin embargo, cuando la explotación abiótica queda para el consumo interno de la región, se consolidan efectivamente economías industrializadas; por el contrario, cuando esta extracción se dirige al exterior, puede caracterizar una economía de enclave primario-exportador con pocos escalonamientos hacia atrás y hacia delante en el mercado interno, cayendo en trampas de especialización hacia sectores intensivos en el uso de la naturaleza y en contaminación y poco generadores de valor agregado. Esta realidad corresponde más a la zona andina.

Las transiciones urbano-industriales de las regiones tienen dos importantes consecuencias socio-ambientales: i) tienen implicaciones en la seguridad alimentaria y ii) se hace necesario impulsar políticas ambientales más activas para 
neutralizar los efectos ecológicos de la minería y la extracción de energía fósil. Con respecto al primer punto, las importaciones de productos bióticos se vieron incrementadas en forma importante: mientras Centroamérica aumentó la importación de biomasa agrícola, correspondiendo la mayor parte a alimentos de consumo humano, de 0,8 MT a 10,2 MT, en los países andinos esta dinámica es aún superior, al pasar de 2,7 MT a 26,1 MT. Es tan evidente esta dinámica que desde 1990 (Consenso de Washington), la región Centroamericana ha importado $230 \mathrm{MT}$ y la Andina 494 MT de biomasa, evidenciando gran dependencia de la importación de alimentos del exterior. Con relación a la especialización hacia lo abiótico la mejor muestra de sus impactos es el incremento de los conflictos ambientales, estando la mayor parte vinculados al sector minero-energético (EJatlas, 2017; Mesoca-Anca, 2016; Pérez-Rincón, 2016). Esto señala la necesidad de fortalecer la política ambiental en las regiones donde se desarrollan los mayores proyectos extractivos.

La disparidad entre la estructura de la extracción doméstica y la estructura del consumo revelan el carácter extractivo de la economía andina y el carácter no extractivo de la economía centroamericana. La economía andina revela un carácter extractivo al ser exportadora neta de materiales con un indicador de intensidad del comercio (X/DMI) de $18 \%$, siendo superior al promedio mundial (14\%). La economía centroamericana por su lado, muestra un carácter no extractivo con un índice (X/DMI) de 7\%. Estos resultados no son inesperados para los países andinos, los cuales desde finales del siglo pasado impulsaron fuertes políticas minero-energéticas que facilitaron la inversión extranjera en todos los países de la región, independientes de su orientación ideológica, tanto las corrientes neoliberales (Colombia y Perú), como las progresistas (Ecuador, Venezuela y Bolivia).

El patrón de especialización adquirido por la economía Andina ha generado un modelo de alta dependencia económica y de explotación no sostenible de los recursos naturales, produciendo un intercambio desigual económica y ecológicamente (IED). Este se identifica de dos maneras: i) por la dirección del flujo neto de recursos materiales en la balanza comercial que tienen una orientación clara hacia el resto del mundo: 6.572 millones de toneladas es el saldo neto de las transacciones comerciales que salen a otros países. ii) Por la tendencia lineal del valor unitario de las exportaciones que crecen más que las importaciones. Para Centroamérica esta realidad es distinta. Mientras el balance comercial arroja un saldo neto de entrada de recursos de 277 MT en todo el período, la dinámica de los precios unitarios de las exportaciones frente a las importaciones mantiene un equilibrio.

Al neutralizar el tamaño de la economía usando los indicadores intensivos, se obtiene que Centroamérica es más intensiva materialmente que la región de los Andes en cuanto al espacio ambiental, pero menos intensiva en términos per cápita. La actividad económica de la región Centroamericana ejerce dos veces más presión ambiental por $\mathrm{km}^{2}$ comparada con la región Andina. Sin embargo, respecto al uso material por persona la región Andina cuenta con un consumo 1,3 veces mayor al consumo centroamericano. Sin embargo, al comparar ambas economías con la Unión Europea se observa que esta es mucho más intensiva en todos los aspectos, evidenciando que para mantener un elevado nivel de vida como el que caracteriza al viejo continente, es necesario el uso intensivo de la naturaleza ya sea del propio territorio o del ajeno como se muestra en sus importaciones.

La economía andina es más eficiente que la centroamericana en términos del uso de materiales. Al comparar la intensidad material por unidad de PIB en términos de DMI, se obtiene que Centroamérica es más intensiva en el uso material que la región Andina: 1,8 kg/US\$ versus 1,6 kg/US\$ en 2012. En el caso de los países andinos, la hipótesis de desmaterialización relativa no se cumple hasta inicios de la década del 2000 y a partir de allí se muestra una tendencia hacia el desacoplamiento material; en Centroamérica, la situación es contraria: hasta mediados de la de 1990 hay desacoplamiento y a partir de allí un ligero acoplamiento material. Sin embargo, 
como lo señala Martínez-Alier (2011), al hacer un balance general entre materialización absoluta y relativa, lo que realmente genera presiones e impactos ambientales no es cuán eficiente se usan los recursos naturales para producir una unidad de PIB, sino cuántos recursos naturales expresados en bienes materiales se usan en total, cuánta contaminación total se genera y cuánto espacio ambiental se ocupa para desarrollar las actividades de producción y de consumo sobre un sistema global que tiene una dotación de recursos, una capacidad de asimilación de desperdicios y un tamaño limitados.

Los procesos de especialización productiva hacia sectores natural-intensivos no son eventos naturales, sino hechos políticos. La especialización requiere que los países desarrollen políticas, cambios normativos, incentivos económicos y otras acciones que los produzcan. En el caso de los países andinos ha habido una clara estrategia de fortalecer el sector minero-energético, sobre todo a partir de 2000 , impulsado por la gran demanda de commodities de China e India que incrementaron los precios de las mismas. En Centroamérica, las políticas hacia el sector minero-energético no han tenido la misma intensidad; incluso Costa Rica genera barreras para limitar su desarrollo dado que su estrategia corresponde a vender el país como gran reserva de biodiversidad. Esto ayuda a confirmar que las decisiones políticas junto a la dotación de recursos naturales y la división internacional del trabajo son factores que ayudan a determinar los perfiles metabólicos de países y regiones.

El análisis del perfil metabólico de la economía andina y centroamericana a través del MFA ha proporcionado imágenes simples y comprensibles sobre el funcionamiento del sistema económico desde una perspectiva biofísica. Esta no solo interesa para fines académicos, sino también es relevante para el debate sobre la sostenibilidad ambiental de la economía y de sus políticas. Sería oportuno por ejemplo utilizar estos instrumentos y resultados como herramienta de evaluación de los logros obtenidos por estos países en términos de los objetivos de desarrollo sostenible (ODS) de Naciones Unidas. Aunque se deben reconocer las limitaciones que presenta esta metodología por su alto nivel de agregación, la realidad de disponer de una base de datos regional se considera un acervo importante para estudiar las relaciones entre la actividad económica y su base material, contribuyendo al estudio del metabolismo social. Sin embargo, esta perspectiva requiere ampliarse, siendo importante complementar esta información metabólica con otros indicadores biofísicos de sustentabilidad como la huella hídrica, la huella ecológica, los análisis energéticos, la apropiación de energía primaria neta, y otros, para entender mejor las presiones de la actividad económica sobre el espacio ambiental en nuestros países.

\section{Referencias}

Ayres, R. U. \& Kneese, A. V. (1969). Production, consumption, and externalities. The American Economic Review, 59(3), 282-297.

Ayres, R. U. \& Simonis, U. E. (1994). Industrial Metabolism: Restructuring for Sustainable Development. Tokyo, Japan: United Nations University Press.

Banco Mundial. (2015). Más Allá del crecimiento económico. Recuperado de http://www.worldbank. org/depweb/spanish/beyond/global/index.html

Behrens, A., Giljum, S., Kovanda, J. \& Niza, S. (2007). The material basis of the global economy: Worldwide patterns of natural resource extraction and their implications for sustainable resource use policies. Ecological Economics, 64(2), 444-453.

Brundtland, G. H. (1989). Nuestro futuro común. Recuperado de http://www.ecominga.uqam.ca/ PDF/BIBLIOGRAPHIE/GUIDE_LECTURE_1/CMMAD-Informe-Comision-Brundtland-sobre-MedioAmbiente-Desarrollo.pdf 
Bunker, S. (1985). Underdeveloping the Amazon: Extraction, unequal exchange, and the failure of the modern state. Chicago, US: University of Chicago Press.

Cabeza, M. (1996). The concept of weak sustainability. Ecological Economics, (17), 147-156.

Carpintero, O. (2007). Pautas de consumo, desmaterialización y nueva economía: entre la realidad y el deseo. Recuperado de http://www.rebelion.org/docs/52577.pdf

Carranza, J. E. y Moreno, S. (2013). Tamaño y estructura vertical de la cadena de producción industrial colombiana desde 1990. Borradores de Economía No. 751. Bogotá, Colombia: Banco de la República.

Carranza, J. E., González, A. y Serna, N. (2014). La relación entre la producción y el comercio exterior de la industria manufacturera colombiana (2000-2010). Borradores de Economía No. 806. Bogotá, Colombia: Banco de la República.

CELADE (Centro Latinoamericano y Caribeño de Demografía, División de Población de la CEPAL). (2014). Base de datos de población. Recuperado de http://www.eclac.cl/celade/proyecciones/ basedatos_BD.htm

CEPAL (Comisión Económica para América Latina y el Caribe). (2015a). Base de datos estadísticos en línea CEPALSTAT. Demográficos y sociales. Recuperado de http://estadisticas.cepal.org/cepalstat/

CEPAL (Comisión Económica para América Latina y el Caribe). (2015b). Base de datos estadísticos en línea CEPALSTAT. Económicos. Recuperado de http://estadisticas.cepal.org/cepalstat/

Clavijo, S., Vera, A. y Fandiño, A. (2012). La desindustrialización en Colombia. Bogotá, Colombia: ANIF.

Cleveland, C. J. \& Ruth, M. (1998). Indicators of dematerialization and the materials intensity of use. Journal of industrial ecology, 2(3), 15-50.

Cuba, E. (2005). Evolución de la economía peruana y perspectivas para 1999. Recuperado de http:// www.gestiopolis.com/economia-peruana-1998-perspectivas-1999/

Daly, H. E. (1996). Beyond growth. The economics of sustainable development. Boston, US: Beacon Press.

Daly, H. E. \& Farsey, J. (2004). Ecological economics. Principles and applications. Washington DC, US: Island Press.

Dittrich, M. \& Bringezu, S. (2010). The physical dimension of international trade: Part 1: Direct global flows between 1962 and 2005. Ecological economics, 69(9), 1838-1847.

Dittrich, M., Bringezu, S. \& Schütz, H. (2012). The physical dimension of international trade, part 2: Indirect global resource flows between 1962 and 2005. Ecological economics, 79(10), 32-43.

Eisenmenger, N. \& Giljum. S. (2006). Evidence from Societal Metabolism Studies for Ecological Unequal Trade. En A. Hornborg \& C. L. Crumley (Eds.), The World System and the Earth System. Global Socio-Environmental Change and Sustainability since the Neolithic (pp. 288-302). Walnut Creek, California, US: Left Coast Press Inc.

EJatlas. (2017). Environmental Justice Atlas. Recuperado de http://www.ejatlas.org/

EUROSTAT (Statistical Office of the European Union). (2007). Economy-wide material flow accounts and derived indicators. A methodological guide. Luxembourg City, Luxembourg: Eurostat.

EUROSTAT (Statistical Office of the European Union). (2013). Economy-wide Material Flow Accounts (EW-MFA). Compilation Guide. Luxembourg City, Luxembourg: Eurostat. 
EUROSTAT (Statistical Office of the European Union). (2015). Base de datos estadísticos en línea EUROSTAT. Recuperado de http://ec.europa.eu/eurostat/data/database

Falconí, F., Vallejo, M. C. y Burbano, R. (2006). Evaluación de los flujos de materiales en el comercio exterior ecuatoriano, colombiano y peruano, a propósito del TLC. Documento de Trabajo, 6(101), s.p.

FAO (Organización de las Naciones Unidas para la Alimentación y la Agricultura). (2015a). FAOSTAT Database. Recuperado de http://faostat3.fao.org/home/S

FAO (Organización de las Naciones Unidas para la Alimentación y la Agricultura). (2015b). Fisheries and Aquaculture Information and Statistics Branch. Recuperado de http://www.fao.org/fishery/ statistics/es

Feenstra, C., Robert, I. \& Timmer, M. (2013). The Next Generation of the Penn World Table. Recuperado de www.ggdc.net/pwt

FICEM (Federación Interamericana de Cemento). (2013). Informe estadístico. Recuperado de http:// www.ficem.org/estadisticas/informe_estadistico_2013.pdf

Fisher-Kowalski, M. (1997). Society's metabolism: on the childhood and adolescence of a rising conceptual star. In M. Redclift \& G. Woodgate (Eds.), The international handbook of environmental sociology (pp. 119-137). Cheltenham, U.K.: Edward Elgar.

Fisher-Kowalski, M. \& Haberl, H. (2015). Social metabolism: a metric for biophysical growth and degrowth. In J. Martínez-Alier \& R. Muradian (Eds.), Handbook of Ecological Economics (pp. 100138). Cheltenham, U.K.: Edward Elgar.

Georgescu-Roegen, N. (1971). Entropy law and the economic process. Cambridge, US: Harvard University Press.

Giljum, S. (2003). Biophysical dimensions of North-South trade: material flows and land use (tesis). Universität Wien, Viena, Austria.

Giljum, S. (2004). Trade, materials flows, and economic development in the South: the example of Chile. Journal of Industrial Ecology, 8(1-2), 241-261.

González M. \& Toledo, V. (2014). The Social Metabolism: A Socio-Ecological Theory of Historical Change. London, UK: Springer.

Gudynas, E. (2011). Desarrollo y sustentabilidad ambiental: diversidad de posturas, tensiones persistentes. En A. Matarán y F. López (coords.), La Tierra no es muda: diálogos entre el desarrollo sostenible y el postdesarrollo (pp. 35-52). Granada, España: Universidad de Granada.

Hák, T., Moldan, B. \& Dahl, A. L. (Eds.). (2012). Sustainability indicators: a scientific assessment (Vol. 67). Washington DC, US: Island Press.

Hornborg, A. (2012). Global ecology and unequal exchange: Fetishism in a zero-sum world (Vol. 13). London, U.K.: Routledge.

Infante, J., González, M. y Toledo, V. (2017). El metabolismo social. Historia, métodos y principales aportaciones. Revista Latinoamericana de Economía Ecologica, 27, 130-152.

Karlson, R. (1995). Recycling in life cycle assesments (tesis doctoral). Chalmers University of Thecnology, Göteborg, Suecia.

Krausmann, F., Fisher-Kowalski, M., Schandl, H. \& Eisenmenger, N. (2008). The global sociometabolic transition. Journal of Industrial Ecology, 12(5-6), 637-656. 
Krausmann, F., Weisz, H., Eisenmenger, N., Schütz, H., Hass, W. \& Schaffartzik, A. (2015). Economywide Material Flow Accounting: Introduction and Guide. Recuperado de https://www.wiso.boku. ac.at/fileadmin/data/H03000/H73000/H73700/Publikationen/Working_Papers/WP_151_Web.pdf

Latorre, S., Farrell, K. N. \& Martínez-Alier, J. (2015). The commodification of nature and socio-environmental resistance in Ecuador: An inventory of accumulation by dispossession cases, 1980-2013. Ecological Economics, 116(2015), 58-69.

Manrique, P. L. P., Brun, J., González-Martínez, A. C., Walter, M. \& Martínez-Alier, J. (2013). The Biophysical Performance of Argentina (1970-2009). Journal of Industrial Ecology, 17(4), 590-604.

Marsh, P. (2012). The New Industrial Revolution: Consumers, Globalization and the End of Mass Production. New Haven, US: Yale University Press.

Martinez-Alier y Roca-Jusmet (2013). Economia Ecológica y Política Ambiental. Fondo de Cultura Económica, 3a. Edición, México D.F.

Martínez-Alier, J. (1995). Indicadores de sustentabilidad y conflictos distributivos ecológicos. Ecología Política, (10), 35-43.

Martínez-Alier, J. (2004). Marx, energy and social metabolism. Encycl Energy, (3), 825-834.

Martínez-Alier, J. (2011). El ecologismo de los pobres: Conflictos ambientales y lenguajes de valoración. Barcelona, España: Icaria.

MESOCA-ANCA (Metabolismo Social y Conflictos Ambientales en países andinos y centroamericanos). (2016). Working Papers Proyecto MESOCA-ANCA, Cali, Universidad del Valle. Recuperado de http:// cinara.univalle.edu.co/index.php/perfilescinara/72-mario-alejandro-perez-rincon

Muñoz, P., Giljum, S. \& Roca, J. (2009). The raw material equivalents of international trade. Journal of Industrial Ecology, 13(6), 881-897.

Nadal, A. (2011). Macroeconomic policies for sustainability. In A. Nadal (Ed.), Macroeconomic policies, Livelihoods and Sustainability Policy Matters (pp. 12-49). Ciudad de México, Mexico: International Union for Conservation of Nature and Natural Resources IUCN.

Ocampo, J. (2001). Un futuro económico para Colombia. Bogotá D.C., Colombia: Editorial Alfaomega.

Ocampo, J. (2011). Seis décadas de debates económicos latinoamericanos. Recuperado de http:// policydialogue. org/files/events/SEGIB-PNUD_Ocampo-final.pdf

Ortíz, C. H. (2016). Diversificación productiva y crecimiento económico. Enfoques teóricos y análisis del desarrollo socioeconómico de Colombia. Cali, Colombia: Programa Editorial Universidad del Valle.

Ortiz, C. H. y Uribe, J. I. (2012). Crecimiento económico, industrialización y empleo: una visión heterodoxa sobre el desarrollo de Colombia y el Valle del Cauca. Cali, Colombia: Programa Editorial Universidad del Valle.

Pérez-Rincón, M. (2006). Colombian international trade from a physical perspective: Towards an ecological "Prebisch thesis". Ecological Economics, 59(4), 519-529.

Pérez-Rincón, M. A. (2008). Comercio internacional y medio ambiente en Colombia: mirada desde la economía ecológica. Cali, Colombia: Programa Editorial Universidad del Valle.

Pérez-Rincón, M. A. (2016). Caracterizando las injusticias ambientales en Colombia: Estudio para 115 casos de conflictos socio-ambientales. Working paper, MA-CA-Univalle-Ol. Recuperado de http:// cinara.univalle.edu.co/index.php/perfilescinara/72-mario-alejandro-perez-rincon 
Pérez-Rincón, M., Crespo-Marín, Z. y Vargas-Morales, J. (2017). Dinámica económica, especialización productiva y conflictos ambientales en países andinos. En C. Alimonda, F. Toro y H. Martín (Coords.), Ecología Política Latinoamericana: Pensamiento Crítico, Diferencia Latinoamericana $Y$ Rearticulación Epistémica (Volumen I) (p. 351-410). Buenos Aires, Argentina: CLACSO.

Pérez, M., Rojas, J. y Ordoñez, C. (Comp.) (2016). Desarrollo Sostenible: Principios, enfoques y lineamientos de política para Colombia. Cali, Colombia: Programa Editorial Universidad del Valle.

Pérez, M. A., Sánchez, L. D. y Zúñiga, M. (2014). Conflicto Ambiental en el río Pance entre diversos usos y usuarios del agua. Cali, Colombia: Programa Editorial Universidad del Valle.

Riechmann, J. (2006). Biomímesis: ensayos sobre imitación de la naturaleza, ecosocialismo y autocontención (Vol. 227). Madrid, España: Edit. La Catarata.

Rossi, M. (Ed.). (2007). Ecos del pensamiento político clásico. Bogotá, Colombia: Prometeo Libros Editorial.

Russi, D., Gonzalez-Martínez, A. C., Silva-Macher, J. C., Giljum, S., Martínez-Alier, J. \& Vallejo, M. C. (2008). Material Flows in Latin America. Journal of Industrial Ecology, 12(5-6), 704-720.

Samaniego, P., Vallejo, M. C. \& Martínez-Alier, J. (2017). Commercial and biophysical deficits in South America, 1990 - 2013. Ecological Economics, (133), 62-73.

Slipak, A. (2012). De qué hablamos cuando hablamos de reprimarización. Buenos Aires, Argentina: mimeo.

USGS (United States Geological Survey). (2015). National Minerals Information Center. Recuperado de http://minerals.usgs.gov/minerals/

Vallejo, M. C. (2010). Biophysical structure of the Ecuadorian economy, foreign trade, and policy implications. Ecological Economics, 70(2), 159-169. https://doi.org/10.1016/j.ecolecon.2010.03.006

Vallejo, M. C. (2015). Perfiles metabólicos de tres economías andinas: Colombia, Ecuador y Perú. Quito, Ecuador: FLACSO.

Vallejo, M. C., Pérez-Rincón, M. A. \& Martinez-Alier, J. (2011). Metabolic profile of the Colombian Economy from 1970 to 2007. Journal of Industrial Ecology, 15(2), 245-267.

Vega, J. M. (2013). Evaluación de la eficacia de las áreas protegidas.: El Sistema de Evaluación Integrada de Áreas Protegidas (SEIAP): resultados de la primera evaluación integrada de los espacios protegidos de la Comunidad de Madrid. Madrid, España: Fundación BBVA.

Victor, P. (1991). Indicators of sustainable development: some lessons from capital theory. Ecological Economics, (4), 191-213.

Weisz, H., Krausmann, F., Amann, C., Eisenmenger, N., Erb, K. H., Hubacek, K. \& Fischer-Kowalski, M. (2006). The physical economy of the European Union: Cross-country comparison and determinants of material consumption. Ecological Economics, 58(4), 676-698. 